\title{
VAJILLAS DE IMPORTACIÓN NO AFRICANAS EN EL NORESTE PENINSULAR (S.V - VII). DISTRIBUCIÓN Y TIPOCRONOLOGÍA
}

\author{
MIGUEL ÁNGEL GONZÁLEZ LÓPEZ \\ Universitat de Barcelona
}

\section{RESUMEN}

El estudio analiza los últimos momentos en la llegada de vajillas finas al noreste de la Península Ibérica (siglos V-VII) teniendo en cuenta categorías cerámicas diferentes de las habituales y mayoritarias importaciones africanas. Son producciones menos conocidas que, sin embargo, desempeñan un papel relevante: entre otras, las "D.S.P. estampadas grises y anaranjadas", la "Terra Sigillata Hispánica Tardía" y la "Late Roman C". En primer lugar, se definen, se determina su distribución y cronología y, posteriormente, se analiza tanto el mayor o menor grado de su presencia en el territorio en cuestión, como las formas documentadas en el mismo. Todo ello a través de contextos diferenciados por cuartos de siglo que evidencian un momento final de recepción de todas ellas a lo largo del siglo VI.

\section{SUMMARY}

The present paper deals with the last phases of arrival, in north-eastern Iberian Peninsula, of late Roman fine wares $\left(5^{\text {th }}\right.$ $7^{\text {th }}$ century AD). The author takes into consideration those pottery productions that unlike the ARS wares which represent the majority of the imports in the western Mediterranean contexts for the period (e.g. "D.S.P.", "Late Hispanic Sigillata", "Phocaean Red Slip / Late Roman C Ware"). The different productions, their distribution and chronology will be presented in the first part of the paper, whereas their typologies and presence in the area of study will be discussed in the second one. The study, which is based on archaeological contexts dated by through sequences of 25 years, puts forward a chronology of $6^{\text {th }}$ century AD for the end of the arrival of these productions.

PALABRAS CLAVE: vajilla tardorromana, difusión, cronología, contexto cerámico, noreste de la Península Ibérica.

KEYWORDS: late Roman wares, distribution, chronology, ceramic context, north-eastern Iberian Peninsula.

\footnotetext{
* Becario del Programa Nacional de Formación del Profesorado Universitario (FPU, Ministerio de Educación y Ciencia). Departament de Prehistòria, Historia Antiga i Arqueologia, Universitat de Barcelona. Diseño gráfico y figuras: Montse Díaz Avellaneda, becaria del Programa Nacional de Formación del Profesorado Universitario (FPU, Ministerio de Educación y Ciencia). Departament de Prehistòria, Historia Antiga i Arqueología. Universitat de Barcelona.
}

Este trabajo pretende analizar el que prácticamente es el último momento en la llegada de importaciones de vajillas finas, de lujo o semilujo, mediterráneas o peninsulares, hacia un territorio que durante el Imperio había sido denominado jurídicamente como Conuentus Tarraconensis: el correspondiente, pues, al noreste de la provincia homónima. El marco temporal es el transcurrido entre los siglos V-VII, es decir, desde los inicios del fin del Imperio de Occidente como entidad política hasta poco antes de la invasión musulmana. Por tanto, estamos hablando de la etapa visigoda que, como se sabe, en nuestra zona de estudio tal vez perduró algo más allá del 711 con el "reinado" de Akhila II aunque, a efectos de nuestro análisis, no llegaremos tan lejos en el tiempo, deteniéndonos algunas décadas antes. De hecho, podremos apreciar una casi absoluta falta de contextos del siglo VII que contengan importaciones de vajilla.

Y para ello, hemos escogido básicamente tres clases cerámicas diferentes de las habituales y mayoritarias importaciones africanas. La razón es la de buscar una mejor aproximación a la distribución y cronología de unos vasos que juegan un importante papel en el área de estudio durante la Antigüedad Tardía. Dicho objetivo conlleva de por sí un mayor acercamiento a unas producciones menos conocidas y tratadas en la bibliografía en comparación con las vajillas africanas, cuya primacía es evidente en la gran mayoría de contextos tardíos en lo referente a importaciones. Asimismo, el estudio procurará que establezcan, confirmen o descarten relaciones comerciales, como precisos indicadores cronológicos de los contextos en los que hacen su aparición. Con esta doble motivación, analizaremos contextos, distribución y espacio temporal de las anteriormente conocidas "Sigillatas Paleocristianas" o "Sigillatas estampadas grises y anaranjadas", hoy más habitualmente denominadas "D.S.P." (Dérivées des Sigillées Paléochrétiennes); de la producción oriental "Late Roman C" o "Phocaean Red Slip Ware", cuya presencia en el área analizada no es tan singular como se creía; y de la "Terra Sigillata Hispánica Tardía", de la cual podría afirmarse lo mismo. Como complemento, determinaremos la hipotética presencia o no (en todo caso testimonial), de otras producciones orientales tardías ("sigillatas" chipriotas o egipcias), que minoritariamente habrían llegado a nuestras costas en 
ese momento para así ampliar un panorama tradicionalmente restringido al de las sigillatas africanas.

El estudio se estructura en un primer encuadre o contextualización de las clases cerámicas tratadas, un resumen sobre aspectos generales de cada una de ellas, centrado en mostrar los criterios macroscópicos para su correcta identificación (pastas, barnices, decoraciones, ...), sus diferentes denominaciones e investigadores que las definieron, el periodo cronológico aproximado que abarcan, sus repertorios tipológicos y, lógicamente, algunos datos sobre su difusión a nivel general. Posteriormente, analizaremos tanto el mayor o menor grado de su presencia en el territorio determinado, como las formas que se documentan en el mismo, a través de contextos diferenciados por cuartos de siglo.

Todo ello se ve reflejado en las láminas, en las cuales, a modo de cuadro recapitulativo, diversas formastipo ilustran visualmente la comparecencia de sus vasos en dicho espacio temporal. Éstas constituyen simplemente una representación gráfica de los ejemplares documentados a partir de perfiles completos que aparecen en distintos manuales o artículos que definieron o compilaron estas producciones ${ }^{1}$. Hay que tener en cuenta que pueden darse ciertas diferencias morfológicas o decorativas en algunos de los vasos considerados tipológicamente como una misma forma, que evidentemente resulta imposible representar con un solo dibujo. En todo caso, el lector podrá realizar una primera aproximación a los mismos a través de esos ejemplos clásicos ${ }^{2}$.

Cabe por último destacar que, ante la incapacidad de la realización de análisis cuantitativos precisos al proce-

\footnotetext{
1 Se ha optado por representar los vasos tal y como aparecen en las obras originales.

2 La relación de la procedencia de las ilustraciones queda como sigue: para las D.S.P. se han representado las formas Rigoir 1 (Fig. 1-3, 5-6), procedente de Rigoir, 1968, 214 (Pl. I); Rigoir 3a (Fig. 1-2, 4-5), procedente de Rigoir, 1968, 217 (Pl. IV); Rigoir 6a (Fig. 1-4, y 6), procedente de Rigoir, 1968, 221 (Pl. VIII); Rigoir 18 (Fig. 1-2, 4-5), procedente de Rigoir, 1968, 214 (Pl. I); Rigoir 15 (Fig. 1-2, 4), procedente de Rigoir, 1968, 225 (Pl. XII); Rigoir 4 (Fig. 1-5), procedente de Rigoir, 1968, 219 (Pl. VI); Rigoir 6b (Fig. 2-4), procedente de Rigoir, 1968, 222 (Pl. IX); Rigoir 3b (Fig. 2), procedente de Rigoir, 1968, 218 (Pl. V); Rigoir 26a (Fig. 2-3), procedente de Rigoir, 1968, 232 (Pl. XIX); Rigoir 9b (Fig. 2, 4, 6), procedente de Rigoir, 1968, 224 (PI. XI); Rigoir 30 (Fig. 2, 4), procedente de Rigoir, 1968, 221 (Pl. VIII); Rigoir 8 (Fig. 2, 4, 6), procedente de Rigoir, 1968, 223 (Pl. X); Rigoir 29 (Fig. 3), procedente de Rigoir, 1968, 233 (Pl. X); Rigoir 35 (Fig. 3), procedente de Rigoir, 1968, 229 (Pl. XVI); Rigoir 24 (Fig. 3), procedente de Rigoir, 1968, 231 (Pl. XVIII); Rigoir 2 (Fig. 3), procedente de Rigoir, 1968, 217 (Pl. IV); Rigoir 5b (Fig. 4), procedente de Rigoir, 1968, 221 (Pl. VIII); Rigoir 26b (Fig. 4), procedente de Raynaud, 1993, 415; Rigoir 36 (Fig. 4), procedente de Raynaud, 1993, 416; Rigoir 20 (Fig. 5), procedente de Rigoir, 1968, 230 (Pl. XVII); y por último la Rigoir 16 (Fig. 5), que procede de Rigoir, 1968, 226 (Pl. XIII).
}

der la información de publicaciones de muy diversa índole, se procurará el mayor acercamiento posible hacia una realidad que, sin duda, estaría mejor definida en caso de disponer sistemáticamente de este tipo de análisis en un número relevante de contextos. Por fortuna, dicha circunstancia está cambiando tras la publicación de diversos trabajos monográficos que analizan la cultura material a través de este proceder, el siguiente paso sería la asunción de un mismo criterio o consenso para llevarlos a cabo.

\section{SIGILLATA SUDGÁLICA TARDÍA GRIS Y ANARANJADA O "D.S.P." (DÉRIVÉES DES SIGILLÉES PALÉOCHRÉTIENNES)}

La vajilla sudgálica estampada gris y anaranjada es una producción tardía que indistintamente emplea cocción reductora u oxidante y cuya característica principal es la citada decoración estampada. Parece ser que derivaría de producciones sudgálicas anteriores, como la Clara B narbonense o la Prelucente, de las cuales se apreciarían claras influencias en la mayor parte de su repertorio formal (Rigoir, 1968, 181). Conocida con apelativos diversos en la bibliografía (Terra Sigillata Visigoda, Terra Sigillata Paleocristiana, Terra Sigillata Anaranjada Gris, Terra Sigillata Gálica Tardía, ...), hoy en día es más común su identificación, a partir de los estudios de J. e Y. Rigoir (Rigoir, 1968; Rigoir, Rigoir, 1971, para la Península Ibérica), como "D.S.P." (Derivées des sigillées paléochrétiennes) ${ }^{3}$. Se documentan tres grandes áreas de producción: Languedoc, con epicentro en Narbona; Bajo Ródano, cuyo taller principal se documentó en Marsella; y Aquitania, original de la zona de Burdeos (Rigoir, 1968, 185).

Entre las formas de Terra Sigillata Hispánica Tardía, han sido representadas la habitual forma 37 tardía (Láms. 1-5), procedente de Mezquíriz, 1961, Fig. 38, núm. 2; la Vila-roma 3.15 (Fig. 2), que procede de Muñoz, 1989, 180; la Ritterling 8 tardía (Fig. 3), procedente de Mezquíriz, 1961, Fig. 11, núm. 18; y finalmente la Dragendorff 36 tardía (Fig. 3), original de Mezquíriz, 1961, Fig. 16, núm. 13.

Por lo que respecta a la producción focea Late Roman $C$, hemos representado las formas Hayes $2 \mathrm{C}$ (Fig. 1), procedente de Hayes, 1972, 328 (Fig. 66, 7); Hayes 3C (Fig. 3-6), procedente de Hayes, 1972, 330 (Fig. 67, 9); Hayes 3E (Fig. 4, 6), procedente de Hayes, 1972, 332 (Fig. 68, 14); Hayes 3D (Fig. 6), procedente de Hayes, 1972, 332 (Fig. 68, 13); Hayes 3H (Fig. 6), procedente de Hayes, 1972, 332 (Fig. 68, 28); y por último, la Hayes 5B (Fig. 6), procedente de Hayes, 1972, 340 (Fig. 70, 2). Asimismo, el único ejemplar de posible vajilla chipriota tardía Late Roman D, forma Hayes 9B (Fig. 4), procede de Hayes, 1972, 380 (Fig. 82, 11).

3 Podemos hallar una buena síntesis de la evolución de la nomenclatura de este tipo cerámico en Caballero, 1972, 205 y, sobre todo, en Fernández Ochoa, García Díaz, Uscatescu, 1992, 122. 
- Grupo narbonense: caracterizado por una mayor proporción de vasos en cocción oxidante respecto a los otros. Las pastas varían del rojo-ladrillo al amarillo ocre; el barniz o engobe, recordando al de las Claras $\mathrm{B}$, es amarillo anaranjado o marrón intenso, casi negro (Rigoir, 1968, 182-183), también rojo-ladrillo o naranja brillante y adherente (a veces presenta un aspecto metálico). La cronología de producción se sitúa c. 350/370-450 ${ }^{4}$ (Raynaud, 1993a, 410). Su difusión se produjo por casi toda la Tarraconense, siendo mucho menor en la costa de la Cartaginense (algún ejemplo en Alicante) y la Baleárica (donde es rara), llegando también, aunque escasamente, a la Mauretania Tigintana. Aparte del taller documentado en Narbona, hay indicios de la existencia de otro importante en Carcasona (Courtieu et al., 1980, 68).

- Grupo provenzal: sus vasos son fundamentalmente reductores, con cierta cantidad de oxidantes; el barniz o engobe es jabonoso al tacto. Decoración sobria si aparece, con ruedecilla y temas simples a punzón, menos rica que la anterior pero más cuidada (Rigoir, 1968, 186). Difundida en todo el Mediterráneo europeo, básicamente en la Galia Narbonense, Liguria y noreste y Levante de la Península Ibérica. En este sentido, resulta curiosa la mayor difusión en Hispania de los productos marselleses con respecto a los del área narbonense, fenómeno que se produce fundamentalmente en la costa de la Tarraconense y Cartaginense hasta el límite con la Bética, en la cual se hallaron evidencias esporádicas. Sigue siendo rara en las Islas Baleares. Su repertorio formal está compuesto por cuencos, platos o jarras de mesa, sin que existan recipientes culinarios, salvo algún mortero excepcional. Su cronología abarca todo el siglo $\mathrm{V}$ (Atlante, I, 1981, 5) apareciendo ya durante los últimos años de siglo anterior (Raynaud, 1993a, 410). Algunos investigadores franceses plantearon la posibilidad de la presencia de una segunda producción desde finales del siglo $\mathrm{V}$, que podría llegar incluso al VII (extremo no del todo confirmado). En ella, desde mediados del siglo VI, la calidad se degradaría sobremanera y el repertorio se empobrecería desapareciendo, por ejemplo, los platos, a la vez que se potenciarían los vasos culinarios (urnas u ollas y morteros. Raynaud, 1993a, 411; Bonifay, Rigoir, 1998, 370). Se trata en definitiva del retorno a los fuegos reductores, que se ponen de moda durante los primeros decenios del siglo $\mathrm{V}$.

\footnotetext{
${ }^{4}$ Mediados del siglo V sería también la fecha adecuada para situar el final de su recepción en el noreste de la Tarraconense, siendo enseguida sustituidas por las provenzales (Bacaria, 1993b, 344). Se exportarían, por tanto, hasta los últimos momentos de su producción.
}

- Grupo aquitano: exclusivamente reductor. Sus piezas presentan engobes oscuros brillantes y adherentes, jabonosos al tacto; los fondos suelen estar decorados (Rigoir, 1968, 185). Predominan formas abiertas, fuentes y platos, sobre todo las Rigoir 1 y 4, también algunas Rigoir 6, 16, 18 y 30 (Rigoir, Rigoir, Mefre, 1973, 223-225). No llega prácticamente a la Península, salvo a algunos enclaves de la costa cantábrica (Uscatescu, Fernández Ochoa, García Díaz, 1994, 188-193) ${ }^{5}$. De hecho, se distribuyó preferentemente en la costa atlántica e interior, entre los valles del Garona y Loira (Rigoir, Rigoir, Mefre, 1973, 208). No se documenta en nuestra área de estudio, excepto un posible ejemplar procedente de Ampurias (Paz, 1991, 208) ${ }^{6}$. Corresponde básicamente al siglo VI (Rigoir, 1968, 192).

\section{DisTRIBUCIÓN DE LA D.S.P. EN EL NORESTE PENINSULAR}

A continuación, como haremos con el resto de producciones, vamos a llevar a cabo una aproximación a la distribución de esta vajilla gala en los yacimientos más relevantes de la zona estudiada desde un punto de vista tipológico, es decir, forma por forma. Africanas aparte, la D.S.P., constituye la producción más abundante en contextos de los siglos V y VI, documentándose tanto en la costa, como en el interior ${ }^{7}$.

\footnotetext{
5 El volumen de fragmentos documentados de la producción aquitana en dichos enclaves no es demasiado elevado, salvo en las termas del Campo Valdés de Gijón, en las cuales, en un contexto de finales del S.V-primera mitad del S.VI, adquieren cierta relevancia por la cantidad y variedad de los ejemplares recuperados (Fernández Ochoa, García Díaz, Uscatescu, 1992, 125-130).

6 Del cual no se tienen más noticias.

7 La siguiente relación sobre la distribución de la D.S.P, extraída fundamentalmente de Caballero, 1972, 208-210; Caballero, Argente, 1975, 134; Járrega, 1992, 1428-1446; y Bacaria, 1993a; sobre todo en lo que concierne a materiales procedentes de excavaciones antiguas o descontextualizados. También, de publicaciones específicas, entre otros, Yañez, 1997, 256-268 (Roc d'Enclar); Aquilué, Burés, 1999, 390-395 (Sant Martí d'Empúries); Uscatescu, 2004, 33-35 (Iesso); Nadal, Serra, 2003, 394-398 (El Capell); Junyent, Pérez Almoguera, 1994, 130-135 (Ilerda); Clariana, Járrega, 1990, 337 y Járrega, Clariana, 1996, 139-141 (Can Modolell); Cela, Revilla, 2004 (Iluro); Clariana, Járrega, 1994, 259 (Torre Llauder); Bacaria et al. 2005, 180 (la Bastida); Enrich, Enrich, 1997, 22 (Cal Sanador); Fábrega, 1989, 157-163 (Tarraco, Vila-roma); Remolà, 2000, 37 (Tarraco, Santa Tecla); Revilla, 2003, 89 y Pérez Suñé, 2003, 226 (Casa Blanca); Prevosti, 1981b, 248 (Can Garí); Guitart, 1970, 154 y 159 (Can Sentromà); Padró, De la Vega, 1989, 1415 (La Colomera); Morral, Nuix, Martín, 1980, 24 (Can Bosch de Basea); Prevosti, 1981b, 376 (Els Caputxins); López Mullor, Fierro, 1994, 118-121 (Darró); Rüger, 1968, 252 (Tarraco, claustro de la catedral). No se incluyen las piezas procedentes de yacimientos que documentaron genéricamente D.S.P. pero cuyas publicaciones no especifican si en variante oxidante o reductora.
} 
En su versión reductora, la primera forma, el plato Rigoir 1 se documenta en Roc d'Enclar (Sant Vicenç d'Enclar, Andorra), Ampurias (el núcleo tardío de Sant Martí), en la Ciutadella de Roses, en Gerunda, en una necrópolis tardía en Solsona, en la ciudad de Iesso (Guissona, Segarra), en la villa de El Capell (Cervera, Segarra), en Ilerda (Paeria), en el santuario de Can Modolell (Cabrera de Mar, Maresme), tanto en la propia ciudad de Iluro como en la villa de Torre Llauder, en Barcino (Plaça del Rei), en la Bastida (Rubí, Vallès Occidental), en Cal Sanador (Òdena, Anoia), en Tarraco (vertederos de Vila-roma y hospital de Santa Tecla, necrópolis del Francolí, etc.) y en la villas de Centcelles (Constantí, Tarragonès) y Casa Blanca (Jesús-Tortosa, Baix Ebre). La copa Rigoir 2 se ha documentado en Solsona, El Capell, villa de Can Garí (Argentona, Maresme) y Tarraco (hospital de Santa Tecla); la Rigoir 3, en Roc d'Enclar, Can Modolell, villa de Can Sentromà (Tiana, Maresme), la Bastida, Tarraco (Vila-roma, Santa Tecla) y Dertosa. Además, su variante 3a, en la cueva de La Colomera (Sant Esteve de la Sagra, Pallars Jussà), Ilerda (Paeria), Iesso, Roses e Iluro; la 3b, también en Ilerda (Paeria), Iesso y Tarraco (Vila-roma); y la $3 \mathrm{c}$, en Solsona y Barcino. La presencia del plato Rigoir 4 se constata en La Colomera, Iesso, Iluro, Barcino (Plaça del Rei, Tinell, ...), Tarraco (hospital de Santa Tecla) y en la Cova de la Guanta (Sentmenat, Vallès Occidental); la del bol o copa Rigoir 5b, sólo en el El Capell.

El gran cuenco Rigoir 6 apareció en Roc d'Enclar, Barcino (Tinell), la Bastida, Sant Cugat del Vallès y Tarraco (Santa Tecla); su variante 6a, en Ampurias, Iesso, El Capell, Ilerda (Paeria), Iluro, Torre Llauder, Barcino (Tinell) y en las villas de Can Bosch de Basea (Terrassa) y Els Antigons (Reus); la 6b, en La Colomera, Ilerda (Paeria), Iesso, El Capell, Iluro, Torre Llauder, Tarraco (Vila-roma) y el yacimiento de Molins Nous (Riudoms, Baix Camp). El plato Rigoir 8 se documenta en La Colomera, Iesso, El Capell, Iluro, Sentmenat, Cal Sanador, Tarraco (necrópolis del Francolí) y villa de Els Antigons. La copa Rigoir 9b se halló en Roc d'Enclar, Camp de la Gruta (Torroella de Montgri, Baix Empordà), Iluro, Torre Llauder, Barcino (Plaça del Rei) y Tarraco (necrópolis del Francolí). El bol carenado o copa Rigoir 15 está bastante extendido, lo tenemos en La Colomera, Ilerda (Paeria), Solsona, Iesso, El Capell, Sant Martí d'Empúries, Roses, Can Madà (Argentona, Maresme), Can Modolell, Iluro, Torre Llauder, villa de Els Caputxins (Mataró), Baetulo, Barcino (Plaça del Rei y Tinell), termas de Sant Boi de Llobregat (Baix Llobregat), villa de Darró (Vilanova i la Geltrú, Garraf), Tarraco (Catedral y necrópolis del Francolí), Reus, Riudoms y en el yacimiento de La Serra (Vila Rodona, Alt Camp).

El bol carenado Rigoir 16 se documentó en El Capell, Iluro y en la necrópolis del Francolí, en Tarra- co. En cambio, la forma Rigoir 18 es una de las más abundantes, documentándose en puntos algo lejanos entre sí como La Colomera, Ilerda (Paeria), Iesso, El Capell, Roc d'Enclar, Sant Martí d'Empúries, Roses, Can Modolell, Iluro, villas de Torre Llauder y Els Caputxins, Barcino (Plaça del Rei, Tinell), Sentmenat, la Bastida, Sant Cugat, Darró, Reus, Tarraco (Catedral, Vila-roma y necrópolis del Francolí) y en diversos enclaves menores en comarcas como el Baix Empordà, ambos Vallès, Bages, Baix Llobregat, Alt Penedés y Baix Ebre. Otras formas con mucha menor relevancia: del cubilete Rigoir 20, evidencias en Iluro; de la urna Rigoir 23, presencia de dos ejemplares, uno procedente de El Capell y otro de Barcino (Plaça del Rei); de la Rigoir 24b, citamos el ejemplar de Tarraco (hospital de Santa Tecla); de la jarra Rigoir 26, evidencias en Tarraco (Vila-roma y Santa Tecla) y en su versión Rigoir 26b, en la Bastida; del mortero Rigoir 29, en Iesso y Tarraco (hospital de Santa Tecla); del platotapadera Rigoir 30, en Ilerda (Paeria), Iluro y Tarraco; de la tapadera Rigoir 31, en Torre Llauder; del cuenco Rigoir 35, en Iluro, villa de Els Caputxins y Tarraco; y finalmente del cuenco con vertedor Rigoir 36, ejemplos también en Iluro, Barcino (Plaça del Rei) y la Bastida. A todos estos ejemplos, cabría añadir la novedosa cantimplora forma "Capell 1", hallada en la villa homónima.

Dentro de la menos común variante anaranjada, el plato Rigoir 1 se documenta en Roc d'Enclar, Iesso, Sant Martí d'Empúries, Camp de la Gruta, Iluro, Torre Llauder, Barcino (Plaça del Rei), villa de Darró y en otros puntos del Vallès Occidental y Anoia. La más minoritaria copa Rigoir 2 aparece en el yacimiento de Santa Margarida de Cabrera (Maresme) y en Torre Llauder. La Rigoir 3, en Roc d'Enclar y en las villas de Can Sentromà y Can Bosch de Basea; además, su variante 3a, en la Ciutadella de Roses, en Ampurias, Tarraco (Vila-roma) y Molins Nous. Ejemplos del gran cuenco Rigoir 6a los tenemos en Roc d'Enclar, Roses, Sant Martí d'Empúries, Darró y en el yacimiento de Can Tarrés (La Garriga, Vallès Oriental); del 6b en Iluro, Tarraco y villa de Casa Blanca. El plato Rigoir 8 se documenta en La Colomera y en el yacimiento de Mas de Dalt (Peralada, Baix Empordà). La copa Rigoir 9, en Roc d'Enclar y su variante 9b, sólo en Tarraco (Vilaroma). El bol carenado o copa Rigoir 15 aparece en Roses, Iluro, Tarraco (necrópolis del Francolí) y en las villas de la Llosa (Cambrils, Baix Camp) y Casa Blanca. También en esta versión oxidada es muy común el hallazgo del bol carenado Rigoir 18, con ejemplos en Roc d'Enclar, El Capell, Ampurias, Iluro, Torre Llauder, Tiana, Sentmenat, Can Bosch de Basea, Tarraco (Vilaroma), Centcelles y Els Antigons (Reus). Al contrario, la jarra Rigoir 27 se documenta exclusivamente en Roc d'Enclar (Andorra). 


\section{TERRA SIGILLATA HISPÁNICA TARDÍA}

En la producción de vajillas finas hispánicas se constata una laguna entre finales del siglo II y el siglo III. Durante la primera mitad de éste, existe una producción calificada como "intermedia", muy disminuida, casi doméstica, realizada por pequeños artesanos y cuyas características son la utilización de los servicios anteriores y degradación en la fabricación de los vasos (Paz, 1991, 229). A partir de la segunda mitad del siglo IV, cierta reactivación permite determinar una producción "tardía", que perdura hasta inicios del siglo VI (Paz, 1991, 230) o primer cuarto del mismo y que constituiría una clara ruptura e innovación respecto a las producciones anteriores altoimperiales (López Rodríguez, 1985, 244-246).

En esta clase cerámica, se distinguieron dos áreas de producción:

- Centros riojanos: sus pastas son rojo claro o anaranjadas, granulosas y porosas (cuarzo, algo de mica...), con barnices rojo oscuro brillantes o densos, o naranjas sin brillo (Paz, 1991, 51-52). Su difusión natural: valle del Ebro y en menor medida, cuenca del Duero, llegando de manera puntual a las costas catalana y valenciana (Paz, 1991, 231) fundamentalmente a través de un único vaso: el cuenco de forma 37 tardía.

- Talleres de la Meseta Norte: pastas rojo o naranja fuerte, finas o granulosas y duras (con cuarzo y mica), a veces de aspecto hojaldrado; barniz rojonaranja o naranja vivo fuerte y denso, con ligero brillo metálico, en algunas piezas agrietado (Paz, 1991, 53). Difusión en su área natural y, de forma más restringida, en la zona de contacto de ésta con el valle del Ebro (Paz, 1991, 231). En general, ambos grupos están presentes en áreas que no recibieron el impacto de las producciones de vajilla africana.

El repertorio tipológico está constituido por formas abiertas, cuencos y platos, siendo escasas las cerradas, pudiendo establecerse una clara separación entre los vasos lisos y decorados. Entre los primeros, aparte de los mayoritarios cuencos y platos, se documentan algunas copas y puntualmente jarras de mesa. La forma de presencia más destacada es el cuenco Ritterling 8 tardío, con mención especial para los también relevantes platos Dragendorff 36 tardío, cuenco de forma 5 tardía, o los platos de formas 82 y 83 . Entre los segundos, predominan casi en exclusiva los cuencos, alguno de gran tamaño. La forma más habitual (con gran diferencia respecto a las otras) es el bol de forma 37 tardía, caracterizador del lapso entre los siglos IV-VI. El resto de vasos, grandes cuencos de formas 42 y 43 , copa de forma 45 , botella de forma 15 y orzas de formas 47 y 48, son escasos (López Rodríguez, 1985, 243). Respecto a los motivos de una decoración realizada en gran medida a molde, en mucho menor grado a través de estampados, se distinguieron varios grupos, en número diverso según cada autor. En cualquier caso, es caracterizadora la presencia de círculos simples o dobles junto con rosetas, franjas horizontales, seriaciones de elementos geométricos, etc. (López Rodríguez, 1985, 44 y ss.).

\section{DistribuCión DE LA T. S. HisPÁNICA TARDÍA EN EL NOR-} ESTE PENINSULAR

Las evidencias de vajilla hispánica tardía en el noreste peninsular son bastante escasas respecto a otras producciones finas del momento, como la T. S. Africana Clara D o las D.S.P. que, por motivos comerciales determinados por las rutas marítimas, llegan con mayor asiduidad. Fundamentalmente, el vaso con mayor salida corresponde a la forma 37 tardía, tal vez debido a un uso singular o por facilidad de adquisición. Veamos pues su distribución.

El bol de forma 37 tardía se ha documentado en la cueva de La Colomera (Padró, De la Vega, 1989, 14-15), Ilerda (Paeria. Junyent, Pérez Almoguera, 1994, 130135), Iesso (Uscatescu, García Jiménez, 2005, 92), Sant Martí d'Empúries (Aquilué, Burés, 1999, 391), Iluro (Cela, Revilla, 2004, 53), villas de Torre Llauder y Can Rafart (Mataró. Prevosti, 1981b, 347) o de Can Sentromà (Guitart, 1970, 150) y Can Riviere (Badalona. Prevosti, 1981a, 172). También, en Barcino y en el monasterio de Sant Cugat (Járrega, 1992, 1450), en la villa de Can Bosch de Basea (Morral, Nuix, Martín, 1980, 20 21), yacimiento del Poble Sec (Coll, Roig, Molina, 1997, 38), taller de Cal Sanador (Enrich, Enrich, 1997, 22) y villas del Tossal del Moro (Corbins, Segrià. Marí, Revilla, 2003, 352), Darró (López Mullor, Fierro, 1994, 124), Centcelles (Járrega, 1992, 1450) y Casa Blanca (Revilla, 2003, 89). Finalmente, en Tarraco hay constancia de su presencia en los vertederos de Vila-roma (Muñoz, 1989, 173-174) y hospital de Santa Tecla (Remolà, 2000, 38), en la torre de la "Antiga Audiència" (Aquilué, 1993a, 123 y 144) y en la Seu del Col-legi d'Arquitectes (Aquilué, 1993b, 109).

El resto de formas documentadas son minoritarias. Adquiere una cierta relevancia la escudilla Ritterling 8 tardía, cuya presencia se constata en la villa de Can Riviere (Prevosti, 1981a, 172), Iluro, Barcino, Egara (Járrega, 1992, 1450) y villas del Tossal del Moro (Marí, Revilla, 2003, 352) y Casa Blanca, donde también se documenta la pátera Dragendorff 36 tardía (Revilla, 2003, 101). Los platos de formas 73 y 83 fueron identificados en Iesso (Uscatescu, García Jiménez, 2005, 92); el cuenco cerrado de forma 42, en Tarraco (claustro de la Catedral. López Rodríguez, 1985, 32) y villa de Casa 
Blanca (Pérez Suñé, 2003, 181). La pequeña copa de forma 45 únicamente apareció en Tarraco (Parc de la Ciutat, Járrega, 1992, 1452); lo mismo que la copa Vilaroma 3.15, que lo hizo en el vertedero homónimo (Muñoz, 1989, 173-174). Finalmente, la olpe o cubilete de forma 85 fue hallada en la villa de Casa Blanca (Pérez Suñé, 2003, 180).

Asimismo, en diversos enclaves de menor rango de comarcas como el Baix Llogregat, ambos Vallès, Anoia, Baix Penedés, Alt y Baix Camp, Ribera d'Ebre y Baix Ebre se documenta mayoritariamente entre las hispánicas tardías la forma 37 tardía y, en algún que otro caso, la Ritterling 8 tardía (Járrega, 1992, 1452).

\section{LATE ROMAN C (SIGILLATA FOCENSE)}

Producción oriental definida inicialmente por F. O. Waagé (Waagé, 1933, 298-301), pero estudiada más exhaustivamente por J. W. Hayes. Como las D.S.P., ha sido conocida con distintas denominaciones en la bibliografía. Originalmente Waagé, desconociendo su procedencia exacta, la bautiza como Late Roman $C$ Ware (Waagé, 1933, 298). Con posterioridad Hayes, una vez cree haber identificado su centro productor, la llama Phocaean Red Slip Ware, proponiendo el abandono del término acuñado por Waagé (Hayes, 1980, 525); poco después, en el Altlante delle forme ceramiche aparece como Terra Sigillata dell'Asia Minore o di Constantinopoli (Atlante, I, 1981, 231). En la actualidad, la denominación inicial de Waagé suele ser la más empleada en la bibliografía no anglosajona, pese a que, desde mediados de los ochenta, F. Mayet y M. Picon confirmaran, a través de análisis arqueométricos, el origen exclusivamente foceo intuido por Hayes y propusieran el que parecía que iba a ser su apelativo definitivo: Sigillée Phocéenne Tardive (Mayet, Picon, 1986, 129). Algunos autores se han decantado por la traducción castellana de este término (p. ej. Serrano, 2005, 305).

Este tipo de vajilla se caracteriza por arcillas duras menos depuradas que las de las claras africanas con impurezas como cal y otros puntitos blancos o amarillentos, siendo de color marrón rojizo (granate o rojo anaranjado claro), con fractura rectilínea. El barniz o engobe es una fina película aplicada irregularmente (que se puede confundir con la pasta), adherente y penetrante, de tono rojo mate o con brillo metálico, principalmente en el interior (Hayes, 1972, 323; Raynaud, 1993b, 502; Martin, 1998, 109). La cocción da a la superficie un color uniforme rojo oscuro y alguna vez rojo anaranjado, a excepción de la cara externa del borde, generalmente de tonos grisáceos oscuros o incluso blanquecinos (Raynaud, 1993b, 502; Martin, 1998, 109). En el exterior, se pueden apreciar algunas vacuolas. El repertorio se reduce a una decena de formas abiertas, de las que dos en concreto, Hayes 3 y 10, son la base de la producción. La decoración es a ruedecilla o mediante estampado. Hayes definió tres etapas diferentes para los vasos decorados: c. 360-450, temas vegetales; c. 440-490, motivos figurados con animales; c. 470-580, figuras humanas y cruces o monogramas (Hayes, 1972, 347-349). Aparte del citado taller principal situado en Focea, se documentó otro en el vecino enclave costero de Grynion ${ }^{8}$ (Empereur, Picon, 1986, 144), también en la costa de la Península Anatólica.

El marco temporal asociado a esta producción se estableció desde el último tercio del siglo IV a finales del siglo VI en sus nueve primeras formas, mientras que la más tardía, Hayes 10, pervive al menos hasta mediados del VII, aunque su distribución es bastante restringida. Abundan en el ámbito egeo, compitiendo con las claras africanas en toda la Pars Orientis. En su momento álgido (siglos V-VI), aparecen además evidencias de su distribución en diversos puntos costeros del Mediterráneo occidental europeo ${ }^{9}$, incluso en las Islas Británicas, aunque ya desde mediados del siglo VI se observa un paulatino retroceso en su llegada a occidente (Reynolds, 1995, 35-36). Su difusión en Hispania es reducida y sólo en el litoral ${ }^{10}$, todo el mediterráneo llegando incluso hasta Lusitania (Delgado, 1975, 287), Gallaecia (Naveiro, 1991, 46) y costa cantábrica (Fernández Ochoa, García Díaz, Uscatescu, 1992, 119). En su momento, se señaló a la "invasión” bizantina y a la inestabilidad provocada en las costas hispanas como causa del cese de las importaciones desde mediados del siglo VI (Nieto, 1984, 547); una hipótesis, como veremos en las conclusiones, actualmente descartada.

Distribución de la Late Roman C EN El nORESte PENINSULAR

Un primer estudio sobre este tipo cerámico realizado por F. X. Nieto $(1984,540-541)$ reconocía la abundancia relativa de los hallazgos del mismo en la Península Ibérica, principalmente entre mediados del S.V y mediados del S.VI. La forma más documentada es el habitual plato Hayes 3, en sus variantes "B" a "H". Queda constancia de ello en la Ciutadella de Roses (Nolla, 1984, 477), en la cual se identificaron las variantes Hayes 3C, Hayes 3H (Járrega, 1992, 1425-1426) y

\footnotetext{
8 No parece que este centro alfarero comercializara sus productos más allá del ámbito local.

9 Según P. Reynolds, no se documentan en la costa africana salvo algún ejemplo muy puntual en Cartago (Reynolds, 1995, 35).

${ }^{10}$ Con alguna excepción, como un par de fragmentos de la forma Hayes 3 documentados en Caesaraugusta (Paz, 1991, 224) que perfectamente pudieron llegar por vía fluvial desde la costa.
} 
Hayes 3E (Nieto, 1993, 202); en el núcleo de Sant Martí d'Empúries (Aquilué, 1997, 89); en la villa de Vilauba (Camós, Plà de l'Estany. Járrega, 1991, 85); y en Camp de la Gruta (Nolla, Puertas, 1988, 37), con la presencia de las variantes Hayes 3B y 3E (Járrega, 1992, 14251426). También en Barcino, en la necrópolis bajo Santa María del Mar y en la Plaça de la Catedral (Nieto, 1984, 542) o bajo el Tinell (Járrega, 1992, 1425), en este caso variante Hayes 3B; en los silos de La Solana (Barrasetas, Járrega, 1997, 132), en sus variantes Hayes 3C y 3D (Barrasetas, 2001, 390); o en la villa de Casa Blanca (Pérez Suñé, 2003, 229). Finalmente, resulta bastante relevante su identificación en diversos contextos de Tarraco, algunos procedentes de la parte alta de la ciudad, variantes Hayes 3B y 3C (Remolà, 2000, 37-45), de la Torre de l'Antiga Audiència, tipos Hayes 3C y $3 \mathrm{E}$ (Aquilué, 1993a, 139), o del circo, también Hayes 3C (Remolà, 2000, 75).

La presencia de otras formas es anecdótica, pero deben ser reseñadas. En Tarraco, procedente del claustro de la catedral, se documenta un plato posible forma Hayes 2C (Nieto, 1984, 542). Asimismo, otros dos de la forma Hayes 5B, en los niveles de amortización del hábitat de la Ciutadella de Roses (Puig, 1998, 178) y en Tarraco (área del circo. Remolà, 2000, 73). Por último, en la villa mausoleo de Centcelles (Constantí, Tarragonès), se identificó otro relacionado con la forma Hayes 10B (Járrega, 1992, 1425).

\section{LATE ROMAN D (SIGILLATA CHIPRIOTA TARDÍA)}

Esta clase cerámica había sido definida en los años cuarenta por F. O. Waagé como Late Roman D a partir de los contextos de Antioquía (Waagé, 1948, 52). En 1972 Hayes, tras bautizarla como "Cypriot Red Slip Ware" y diferenciarla de una producción altoimperial antecesora de ésta (Hayes, 1972, 371; 1980, 528), realizó una aproximación más exhaustiva. Características técnicas: la pasta es fina y suave, sin granos visibles, de fractura limpia. El grado de cocción y, por tanto, el color varían enormemente, oscilando entre el amarillo y varias tonalidades (naranja, marrón y rojo) hacia un profundo marrón oscuro, púrpura y sepia; en todo caso, el tono rosado o marrón es el más común. Como en el caso de la Late Roman C, una fina capa de barniz cubre toda la superficie del vaso. Éste es de similar naturaleza que la arcilla, con la que tiende a concordar en tono aunque algo más oscuro. Posee una apariencia mate en las piezas poco cocidas, que adquiere un lustre metálico en las sobrecalentadas (Hayes, 1972, 371).

$\mathrm{Su}$ repertorio formal evidencia un alto grado de estandarización. Las formas más tempranas son fundamentalmente platos medianos con pie bajo (formas
Hayes 1 y 2); en las tardías (forma Hayes 9), éste simplemente se insinúa, siendo casi planos. En contadas ocasiones aparece una serie paralela de pequeños cuencos (formas Hayes 3 y 5). Un tercer tipo formal, con gran volumen de fabricación en las últimas fases, es un cuenco "palangana" profundo con o sin asas (formas Hayes 7, 9, 10), presumiblemente para uso doméstico (Hayes, 1972, 372).

La decoración estándar, realizada a ruedecilla, es tosca. Dos largos trazos cubren la totalidad de la pared junto con una o más bandas curvadas incisas, a menudo aplicadas de modo "errático" e interrumpidas por huecos. Un aspecto peculiar en estos vasos es la presencia en los bordes de muchos platos (principalmente los tardíos) de una corta línea profunda incisa, ondulada, que podría ser calificada como la "marca de fábrica" de los productos chipriotas. Asimismo, los fondos de ciertos platos, por ejemplo los correspondientes a las formas Hayes 2 y 9, presentan estampaciones. (Hayes, 1972, 372).

Datación: oscila entre finales del siglo IV, en las producciones más precoces, hasta finales del VII; su exportación se constata principalmente desde mediados del siglo V hasta finales del VII (Atlante, I, 1981, 239). La evolución de este grupo es bastante estable excepto una fase de cierta decadencia técnico-formal a mediados del siglo VI. Su difusión se produjo principalmente en el Mediterráneo oriental, costas del Egeo, por descontado en Chipre, Levante sirio-palestino, Egipto y Cyrenaica (Hayes, 1972, 385). Muy rara en occidente, su presencia, circunscrita fundamentalmente a los platos Hayes 2 y 9 , se atestigua a grandes rasgos en enclaves en los que la vajilla Late Roman $C$ es asimismo relevante, como Marsella, Baelo Claudia, Cathago Spartaria, Lucentum (Reynolds, 1995, 36) o Valentia (Pascual et al., 1997, 185), no llegando, a diferencia de la vajilla focea tardía, a las costas atlánticas.

Distribución de la Late Roman D EN El nORESTe PENINSULAR

Los únicos ejemplares identificados hasta el momento fueron los platos Hayes 2 en Iluro (Járrega, 1991, 88), en el santuario de Can Modolell (Cabrera de Mar. Járrega, Clariana, 1994, 333) y en Dertosa (Járrega, 1992, 1427). También los Hayes 9b en el cardo maximus de Iluro (Revilla et al., 1997, 104) y posiblemente en un cardo minor paralelo al anterior (Járrega, Clariana, 1994, 334). Aparte de éstos, sólo cabría mencionar el ejemplo hallado en el yacimiento de Molins Nous (Riudoms. Járrega, 1992, 1427).

Alguna de estas adscripciones podría ser, cuanto menos, problemática. El ejemplo de Can Modolell presenta un pie alto extraño para lo que es la morfología habitual de los platos de esta producción, su borde 
estriado podría sin embargo concordar con alguno de los individuos representados por Hayes (Hayes, 1972, Fig. 80 , Forma $\left.2, n^{\circ} 1\right)$. En el caso de la pieza procedente del cardo maximus de Iluro, en un principio adscrita con certeza a la producción de vajilla chipriota (Revilla et al., 1997, 104), fue catalogada posteriormente como "posible", señalándose asimismo la ausencia de la decoración propia de esta forma (Cela, Revilla, 2004, 53). A primera vista, el perfil representado de este vaso podría además resultar demasiado plano respecto a los ejemplares mostrados por Hayes, algo más profundos. Finalmente, el fragmento hallado en un cardo minor de la misma ciudad, fue descrito como un perfil atípico dentro de esta producción oriental que podía ser identificado con la forma Hayes $9 \mathrm{~b}$, pero sin poderse asegurar su procedencia chipriota (Járrega, Clariana, 1994, 334).

\section{SIGILLATA EGIPCIA B}

Producción definida por Hayes (1972) como "Egyptian Red Slip Ware”, el cual advirtió imitaciones egipcias de claras africanas con ciertas características que le daban entidad propia. Así, diferenció las variantes "A" (conocida también como "Coptic Red Slip Ware"), "B" y "C", ésta definida por Waagé en los años treinta como una imitación de su "Late Roman B" (que correspondería a la Clara A / D de Lamboglia).

El tipo "B" corresponde, según Hayes, a una serie diversa de vasos egipcios, fabricados en diferentes talleres, caracterizados por una pasta rojiza espesa y grosera, con partículas micáceas y un bruñido denso también rojo (Hayes, 1972, 397).

Las formas son numerosas y muy diversas, algunas copian vasos de claras africanas e incluso presentan motivos estampados tomados de tipos africanos degradados. Suelen ser platos y algún bol; las más precoces copian vasos africanos desde finales del siglo IV-inicios del V; las más tardías, comunes en el siglo VII, muestran marcadas similitudes con el tipo egipcio "C". A juzgar por su relevante presencia en la zona del Delta del Nilo, sería plausible la localización de sus talleres en esta zona (Hayes, 1972, 398-399).

\section{Distribución de la Sigillata Egipcia B EN El nORESTE} PENINSULAR

Hasta ahora, la única evidencia de este tipo en toda el área noreste se hallaba en Iluro, donde en un conjunto del siglo V se habría identificado el plato Hayes, 1972, fig. 88 b / c (Járrega, 1991, 88; Járrega, Clariana, 1994, 335). Sin embargo, dicha atribución fue dada como insegura con posterioridad (Járrega, 2000, 474).

$\mathrm{Y}$ es que, al igual que sucede con la vajilla chipriota Late Roman D, la presencia de vajillas orientales en el
Mediterráneo occidental, más allá de la producción focense Late Roman $C$, puede resultar bastante dudosa. En este sentido, hemos podido constatar cómo algunos especialistas cuestionan la verdadera llegada de esta producción fina egipcia a las costas occidentales ${ }^{11}$. Hayes, en la revisión de su manual tipológico, se refiere al caso que nos ocupa, el tipo egipcio "B", como una producción no muy definida, cuyos límites exactos tendrían que determinarse sin poder confirmar entonces la existencia de varios talleres regionales (Hayes, 1980, 530).

\section{SIGILLATA EGIPCIA C}

Hayes dio este nombre a un heterogéneo grupo de vasos reconociéndoles una atribución egipcia por conveniencia, ya que podrían haber sido fabricados en áreas diversas. Sus principales características son la arenosa textura de la arcilla, de color naranja o marrón, producida aparentemente por la cocción, y el espeso barniz rojo de apariencia difuminada, ligeramente micáceo, bruñido y lustroso en el interior y borde del vaso, más delgado y deslustrado o apagado en el exterior, donde está bruñido con menos cuidado. Los desgrasantes son limos, cuarzo, varios granos arenosos oscuros y mica pequeña (Hayes, 1972, 399).

Las formas principales son páteras abiertas, quizás imitación del plato Hayes 105 de la T. S. Africana; cuencos poco profundos con bordes prominentes, posiblemente derivados de la forma Hayes 104c; platos cerrados de base plana que copian la forma Hayes 9 chipriota; y cuencos carenados poco profundos con bordes similares a sus homólogos del tipo "B" (Hayes, 1972, 400).

La decoración estándar en los platos consiste en dos surcos o pares de surcos separados en el fondo interno, combinados, en ejemplares puntuales, con estampaciones groseras de palmetas o rosetas (Hayes, 1972, 400). Cronología: aparecen sólo en contextos del siglo VII, puede que surgieran como sustitutos de otras producciones finas tardías que habrían desaparecido del mercado. Según Hayes, es posible que fueran fabricados hasta el 700 o incluso más tarde (Hayes, 1972, 401). Su difusión se produjo sólo en la desembocadura del Nilo.

\section{Distribución de la Sigillata EgipCia C en El NOREste PENINSULAR}

Únicamente había constancia de su existencia en el yacimiento de Els Vinyets (Vila-Rodona, Alt Camp), concretamente del plato Hayes, 1972, fig. 89 b (Járrega, 1992, 1428). Aparte de remitir a las observaciones efec-

\footnotetext{
${ }^{11}$ Comunicación personal del Dr. Archer Martin (American Academy in Rome), la cual agradecemos desde estas líneas.
} 


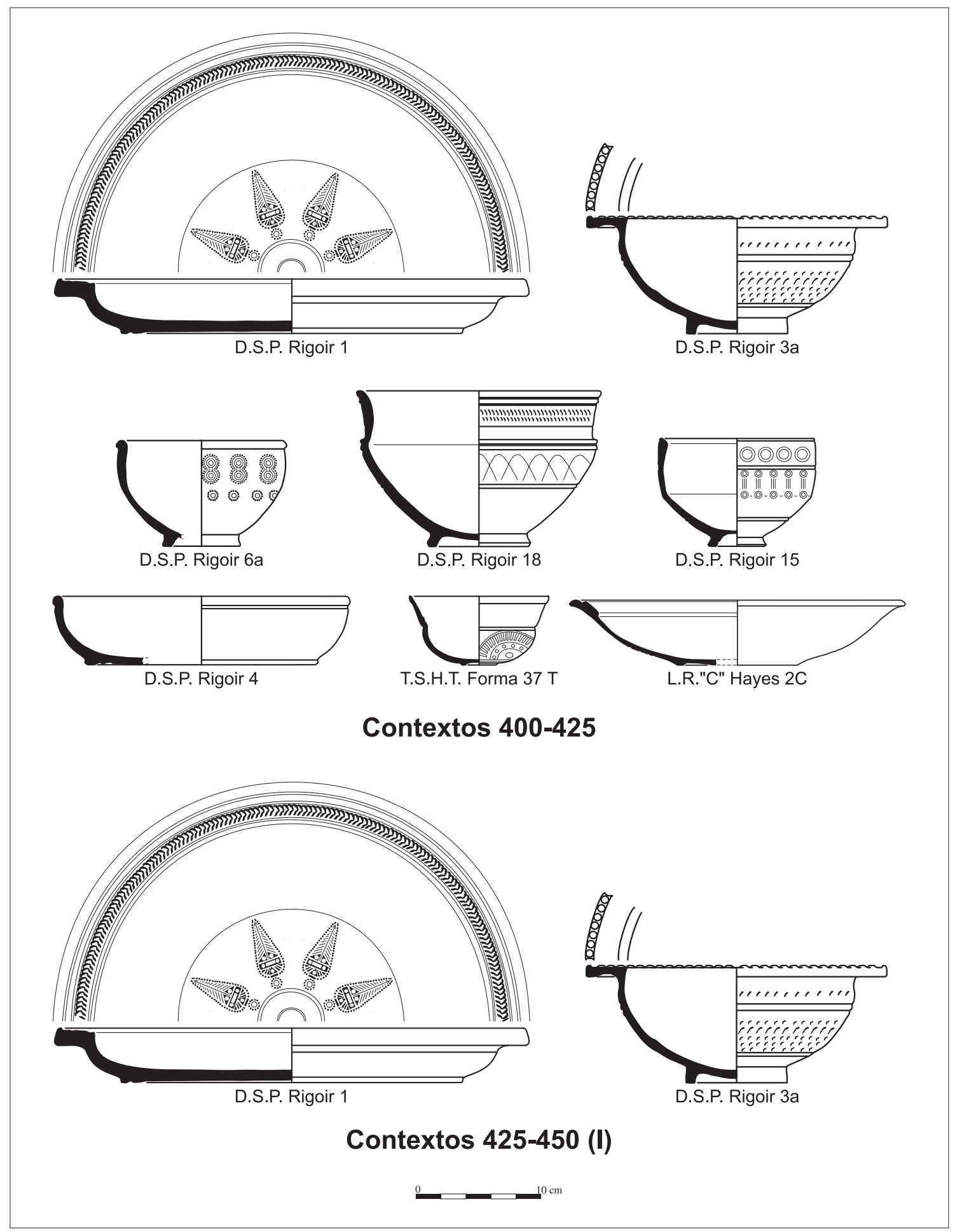

Figura 1. Recapitulación de los contextos 400-425 y 425-450 a través de "formas-tipo" de las producciones analizadas. 
tuadas para el tipo anterior, conviene añadir las realizadas en su momento por Hayes, que atribuyó a la "sombría" (sic) vajilla egipcia "C" una distribución local o regional, ya que diversos fragmentos procedentes de Chipre y Siria, en un principio atribuidos a este tipo de vajilla, pudieron no corresponder a la misma producción que los identificados como egipcios en su área original (Hayes, 1980, 530).

\section{CONTEXTOS CERÁMICOS DE VAJILLAS DE IMPORTACIÓN NO AFRICANAS (S.V-VII)}

Una vez conocida la distribución geográfica de las vajillas estudiadas, procederemos a realizar otro tipo de análisis, en este caso cronológico. Observados los contextos, fundamentalmente pertenecientes a los siglos $\mathrm{V}$ y VI, apreciaremos si estas producciones llegan o no al siglo VII y, por tanto, el espacio temporal que cubrieron hasta su total desaparición en el área analizada.

\section{Contextos 400-425}

En contextos de inicios del siglo V, la villa de Els Hospitals (El Morell, Tarragonés), establecimiento rural en el territorium de Tarraco, proporciona escasos fragmentos de D.S.P., en concreto de la forma Rigoir 3. No apareció ninguno de T. S. Hispánica Tardía (Macias et al., 1997, 164).

En el vertedero tardorromano de la plaza mayor de Sant Martí d'Empúries, con una cronología del primer cuarto del siglo V, se hallaron nueve ejemplares de D.S.P. Gris, concretamente de las formas Rigoir 1 y 18 , procedentes de los talleres del Languedoc, además de la forma Rigoir 6a de la versión oxidada. En total, constituirían un 16,36 \% de toda la vajilla de mesa documentada. La T. S. Hispánica Tardía está representada por un único ejemplar, la habitual forma 37 tardía, estando ausente la Late Roman C (Aquilué, Burés, 1999, 391).

Otros conjuntos afines datados en el primer cuarto del siglo $\mathrm{V}$ presentan similares proporciones. En el del Claustro de la Catedral de Tarragona hay presencia tanto de D.S.P., platos Rigoir 1 y 4, copas Rigoir 15 y cuencos Rigoir 18 (Rüger, 1968, 255), como de T. S. Hispánica Tardía, concretamente del gran bol de forma 42 (López Rodríguez, 1985, 32) ${ }^{12}$. La Late Roman C estaría asimismo representada por un posible ejemplar de la forma Hayes 2C (Nieto, 1984, 542). La presencia de esta última sería bastante precoz respecto al momento de exportación de la vajilla focense en el Mediterráneo occidental, establecido a partir de mediados del siglo V.

\footnotetext{
${ }^{12} \mathrm{Ch}$. Rüger lo había identificado como una variante de la forma 37 tardía (Rüger, 1968, 252).
}

Además, según P. Reynolds (Reynolds, 1995, 35), las formas tempranas, platos Hayes 2, Hayes 3A y Hayes $3 \mathrm{~B}$, no fueron exportadas, aunque como veremos, algunos autores identificaron esta última variante en diversos enclaves litorales del área analizada (Barcino y Tarraco, también en Valentia). Teniendo esto en cuenta y el hecho de que la pieza haya sido siempre recogida en la bibliografía como "posible" (Nieto, 1984, 542; Járrega, 1992, 1425; Reynolds, 1995, 162; Aquilué, 1997, 87), deberíamos tomar esta atribución con cierta cautela, pese a la gran similitud de su perfil con el representado por J. W. Hayes (Hayes, 1972, Fig. 66, 7).

\section{Contextos 425-450}

En la villa de Darró (Vilanova i la Geltrú, Garraf), en un depósito formado hacia el segundo cuarto del siglo V, es abundante la presencia de D.S.P. de procedencia languedociense: en versión reductora tenemos las copas Rigoir 15 y cuencos Rigoir 18; en la oxidante, el plato Rigoir 1 y el cuenco Rigoir 6a (López Mullor, Fierro, 1994, 118-121). La producción hispánica tardía también está presente con la forma 37 tardía (López Mullor, Fierro, 1994, 124).

En la calle Vila-roma de Tarragona se halló un pozovertedero cerámico datado muy precisamente entre los años 440 y 450 , debido a la coexistencia en un mismo conjunto cerrado de una mayoría de materiales de la primera mitad del siglo $\mathrm{V}$ junto con otros minoritarios posteriores a esa fecha, aparte de la ausencia de importaciones más tardías como podrían ser los platos de la producción Late Roman C (TED’A, 1989, 425 y 427). Sin embargo, actualmente no se descarta una eventual continuidad del mismo hasta el tercer cuarto de siglo $\mathrm{V}$ (Reynolds, 1995, 281), pensándose por tanto en una datación amplia de mediados del mismo siglo (Remolà, 2000, 48).

En dicho vertedero se documentan las D.S.P. grises y anaranjadas en una proporción del $12,72 \%$ respecto al resto de la vajilla de mesa, concretamente el plato Rigoir 1, las copas Rigoir 3a y 3b, los cuencos Rigoir 6 y 9, el bol carenado Rigoir 18 y la jarra Rigoir 26 (Fábrega, 1989, 157-163). La T. S. Hispánica Tardía también está presente, en menor proporción (5,3\%), con la siempre habitual forma 37 tardía y una novedosa copa denominada como forma "Vila-roma 3.15", muy parecida a la habitual copa Lamboglia 1/3 de la producción sudgálica T. S. Lucente (Muñoz, 1989, 173-174).

\section{Contextos 400-450}

En el área noreste, concretamente en la villa de Puig Rodon (Corçà, Baix Empordà), en un contexto que se encuadra en la primera mitad del siglo $\mathrm{V}$, se documenta únicamente D.S.P. (el bol Rigoir 18), en una proporción 

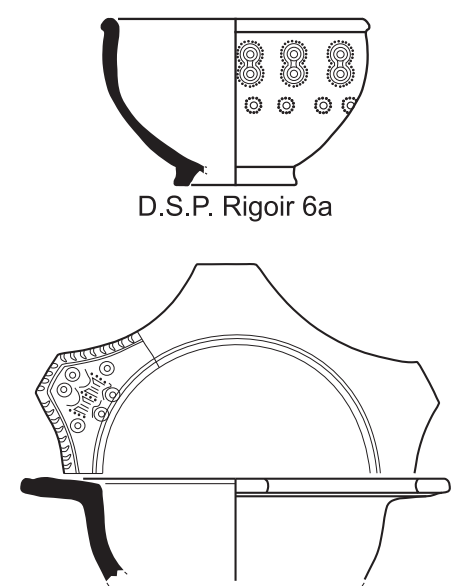

D.S.P. Rigoir 3b
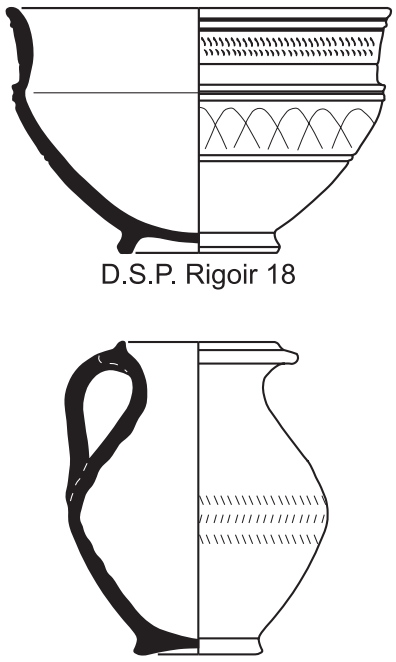

D.S.P. Rigoir $26 a$
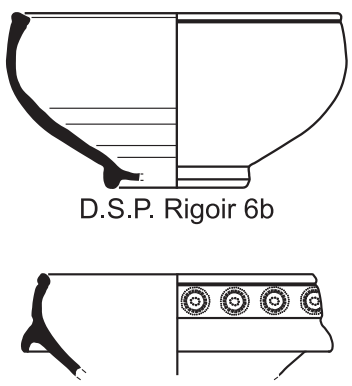

D.S.P. Rigoir $9 b$

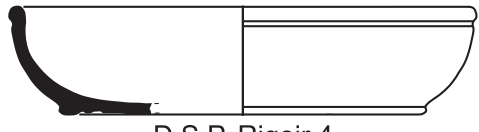

D.S.P. Rigoir 4

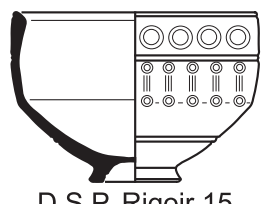

D.S.P. Rigoir 15

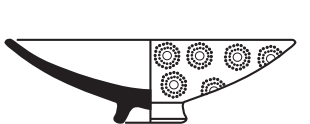

D.S.P. Rigoir 30

T.S.H.T. Forma $37 \mathrm{~T}$

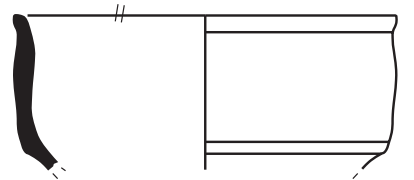

T.S.H.T. Vila-roma 3.15

Contextos 425-450 (II)

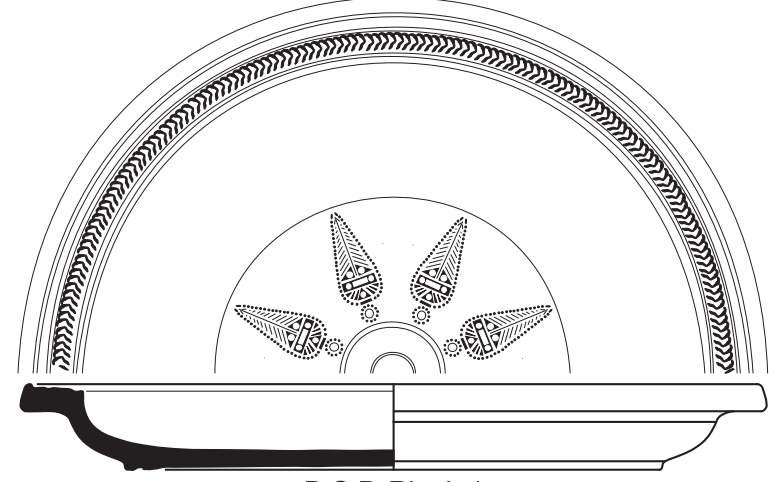

D.S.P. Rigoir 1
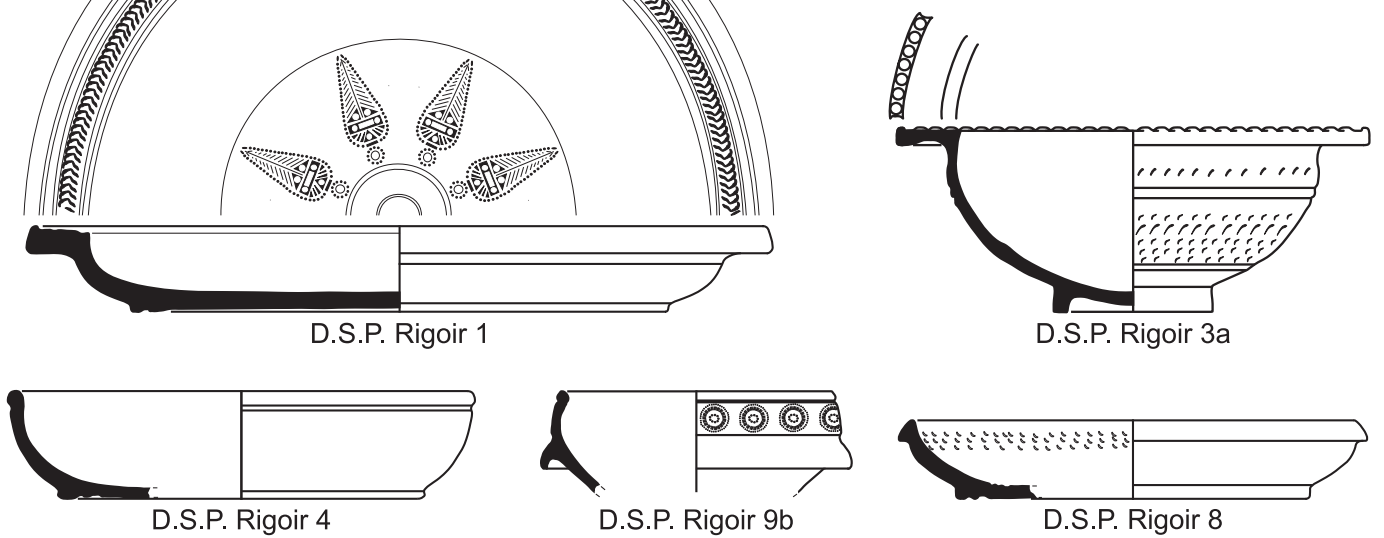

D.S.P. Rigoir $9 b$

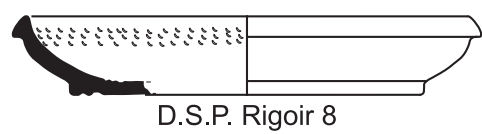

Contextos 450-475 (I)

Figura 2. Recapitulación de los contextos 425-450 y 450-475 a través de "formas-tipo" de las producciones analizadas. 
de tan sólo el 0,29 \% del total de las vajillas. En el mismo yacimiento, pero en niveles con cronología de mediados del siglo V, aparecen las formas Rigoir 3, 6a y 18 (Nolla, Casas, 1990, 203, 206, 212).

No demasiado lejos de allí, unas excavaciones de urgencia en la carretera de L'Escala a Sant Martí d'Empúries desenterraron una necrópolis tardorromana datable en la primera mitad del siglo $\mathrm{V}$ que únicamente aportó D.S.P. entre los tipos cerámicos que nos interesan. Se diferenciaron las formas Rigoir 1, 3, 4, 6, 15 y 18 , que conforman un relativo alto porcentaje $(22,4 \%)$ del total de la vajilla de importación (Llinàs, 1997, 154 y 164).

Más al sur, el yacimiento del Poble Sec (Sant Quirze del Vallès, Vallès Occidental) proporcionó treinta fragmentos de D.S.P. (Rigoir 1, 6, 18) y diecinueve de T. S. Hispánica Tardía, entre los cuales se identificaron tres cuencos de forma 37 tardía. Todos éstos, tanto los primeros como los segundos, conforman un conjunto datable en la primera mitad del siglo V (Coll, Roig, Molina, 1997, 38).

Ilerda, uno de los puntos geográficos más interiores del estudio, también documenta estas producciones. Un conjunto exhumado bajo el edificio de La Paeria, atribuido a la primera mitad del siglo $\mathrm{V}$ y cuya cronología confirmaría la destrucción de la ciudad (según las fuentes en $449^{13}$ ) por parte de suevos y bacaudae (Junyent, Pérez Almoguera, 1994, 148), evidencia una mayor relevancia de las vajillas sudgálicas estampadas tardías. Con un origen languedociense en la totalidad de los casos y cocidos en atmósferas reductoras, se documentan los tipos Rigoir 1, 3a, 3b, 6a, 6b, 15a, 15b, 18 y 30. En menor medida aunque bien representada, también aparece la T. S. Hispánica Tardía: como es habitual con la forma 37 tardía (Junyent, Pérez Almoguera, 1994, 130-135).

\section{Contextos 450-475}

En Iluro, en un primer nivel de amortización del sector oeste del cardo maximus (excavación C/ Sant Cristòfol 12, 99/00), datado entre mediados y el tercer cuarto del siglo V, se exhumó un conjunto que incluía evidencias de D.S.P., concretamente del cuenco Rigoir $6 \mathrm{~b}$ (Cela, Revilla, 2004, 75).

En los decenios centrales del siglo, en el recinto de culto de la parte alta de Tarraco, un vertedero en el solar del antiguo Hospital de Santa Tecla (de cronología ligeramente posterior al de Vila-roma) proporcionó otro lote cerámico destacable. En el mismo, como es habitual, dentro de la vajilla fina predominan las producciones africanas, alcanzando sin embargo una cierta relevancia

\footnotetext{
${ }^{13}$ Isid. Hist. Sueb. 87; Hidac. Olymp. XXV, 671-675.
}

la presencia de las sudgálicas $(18,20 \%)$ con un repertorio bastante variado: platos Rigoir 1, 4 y 8, copas Rigoir 2, 3 y 9, cuencos Rigoir 6 y 35, urnas Rigoir 24, jarras Rigoir 26 y mortero Rigoir 29. Los tipos hispánicos y orientales estaban también presentes, pero en menor medida: cuencos de forma 37 tardía en T. S. Hispánica Tardía (2,91\% de las vajillas tardías); y platos Hayes 3 de la producción focense Late Roman C (0,24 \%. Remolà, 2000, 37-38).

A este mismo momento pertenece un contexto procedente de un enclave que constituye el límite geográfico meridional de nuestro estudio. En niveles de regularización de la última fase de la villa de Casa Blanca (Jesús-Tortosa, Baix Ebre) se documenta T. S. Sigillata Hispánica Tardía y D.S.P., con la novedosa preeminencia de la primera $(11,22 \%$ de toda la vajilla) sobre la segunda, que es meramente testimonial $(0,82 \%)$. La vajilla hispánica documenta los cuencos de forma 37 tardía, Ritterling 8 tardía y las páteras Dragendorff 36 tardía; mientras que la D.S.P. estampada gris, únicamente el bol Rigoir 6 (Revilla, 2003, 89 y 101). Se alude asimismo a la presencia de un cuenco de forma 6 (equivalente a la forma 5 de la clasificación inicial de Mezquíriz, 1961), pero cuyo perfil (Revilla, 2003, 105: Fig. 39, 3) por dimensiones, curvatura e inclinación del labio inferior externo e insinuación de la carena recuerda más bien al de la pátera Dragendorff 36 tardía.

\section{ConteXtos 475-500}

De nuevo en Iluro, otro nivel de amortización del cardo maximus, situado en su lado este (misma excavación anterior) y datado en la segunda mitad avanzada o finales del siglo $\mathrm{V}$, aporta también evidencias de estas producciones. En primer lugar, de D.S.P. anaranjada (5,2 \% de la vajilla tardía), con los cuencos Rigoir 6; también, de su variante gris $(3,4 \%)$, con las copas Rigoir 15. La T. S. Hispánica Tardía está representada testimonialmente por un fragmento (Cela, Revilla, 2004, 77). Otra zona de la misma ciudad aportó un conjunto cercano a finales del siglo $\mathrm{V}$. La excavación de una antigua taberna (C/ Pujol 47, 1998) evidenció un primer estrato de nivelación con presencia de D.S.P. gris, forma Rigoir 16 (Cela, Revilla, 2004, 136).

En Tarraco, en la "Antiga Audiència", en la fase en la cual la torre es utilizada como basurero, último cuarto del siglo $\mathrm{V}$, aparece Late Roman $C$ en un número ciertamente considerable respecto a lo que es habitual: 8,12 $\%$ de todas las vajillas. Son diversos fragmentos correspondientes a cinco individuos de la forma Hayes $3 \mathrm{C} \mathrm{y}$ uno de la Hayes 3E. Entre la D.S.P. gris y anaranjada ( $19,82 \%$ de los vasos finos), aparecen diversos ejemplares del plato Rigoir 1, copa Rigoir 3a, cuenco Rigoir 6b, copa Rigoir 18 y el plato-tapadera Rigoir 30. La T. S. Hispánica Tardía $(5,40 \%)$ está representada de nuevo 

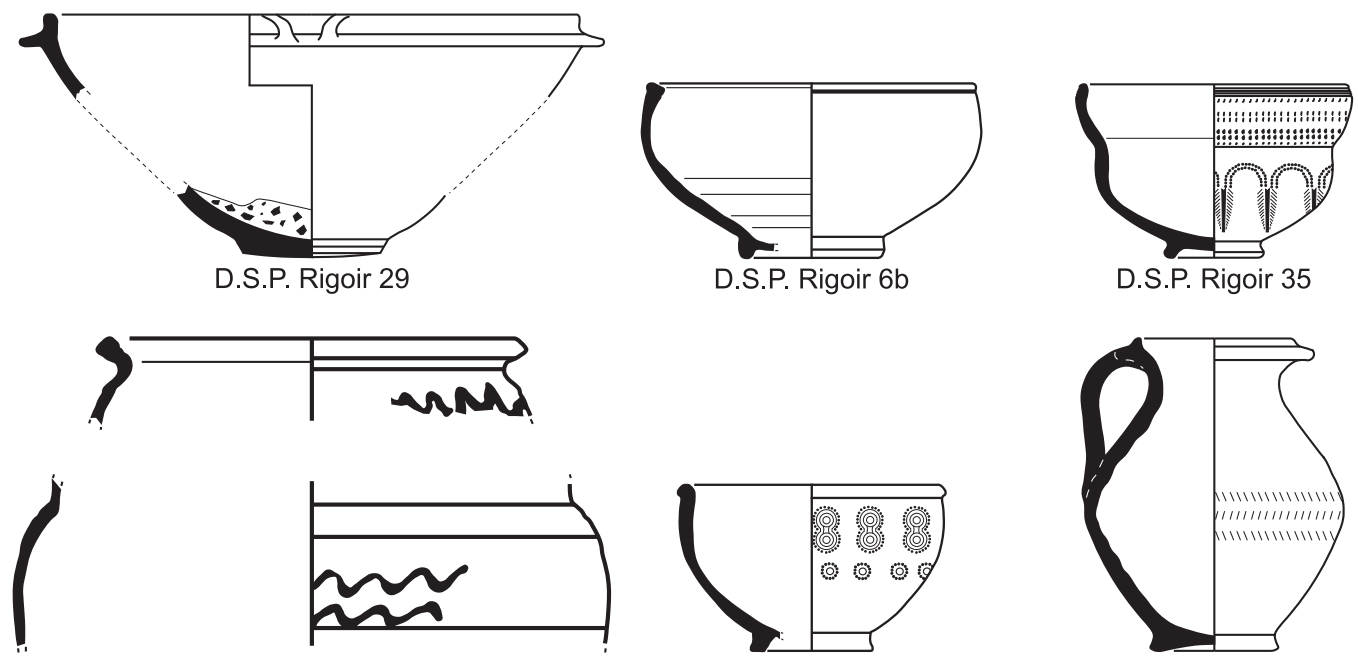

D.S.P. Rigoir 24

D.S.P. Rigoir $6 a$
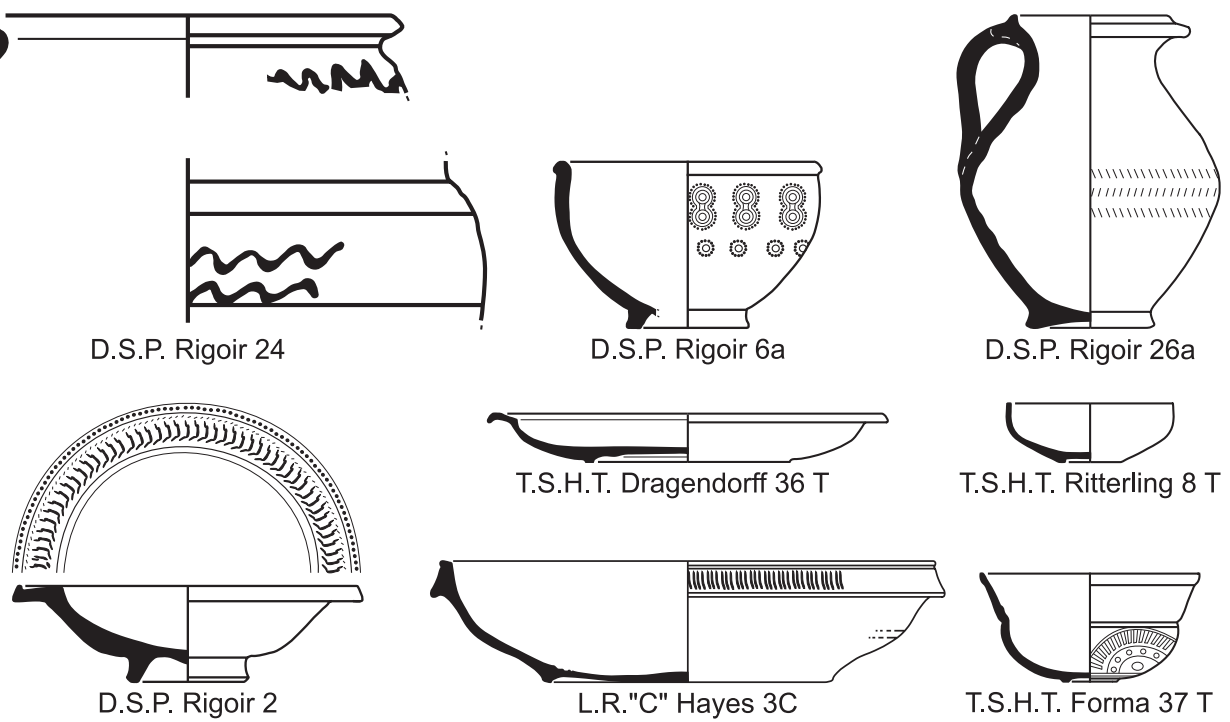

T.S.H.T. Ritterling $8 \mathrm{~T}$
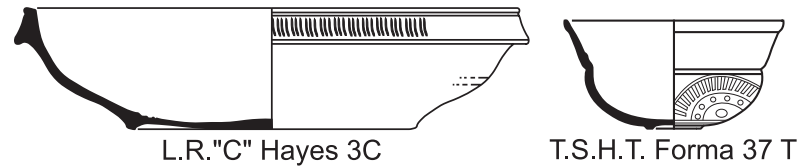

Contextos 450-475 (II)
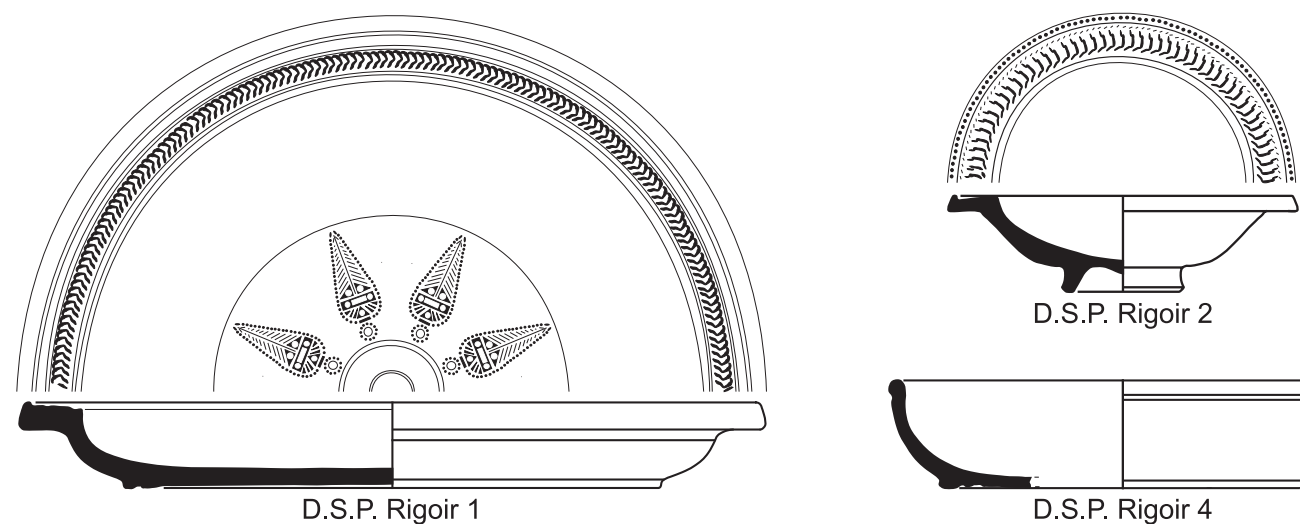

Contextos 475-500 (I)
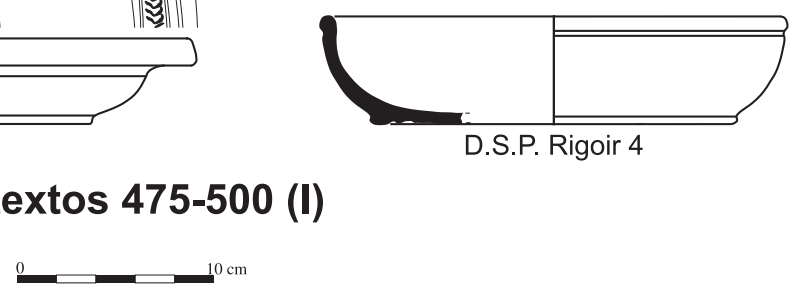

Figura 3. Recapitulación de los contextos 450-475 y 475-500 a través de "formas-tipo" de las producciones analizadas. 
por el bol de forma 37 tardía (cuatro ejemplares. Aquilué, 1993a, 139-144).

En la carretera de L'Escala a Sant Martí d'Empúries, una segunda fase (c. 480-principios del siglo VI) correspondiente a un vertedero proporcionó cerámicas estampadas D.S.P. de formas Rigoir 1, 4, 6 y 18 en un porcentaje menor que el del momento anterior, ya que alcanzan un $12,23 \%$ del total de vajilla fina importada (Llinàs, 1997, 155 y 164).

Un último ejemplo correspondiente a finales del siglo V lo tenemos en la Església Vella de Sant Menna (Sentmenat, Vallès Occidental), de donde se extrajeron diez fragmentos de D.S.P. (Rigoir 2, 3, 5b, 15, 18). Pese a ello, en este contexto es notable el dominio de las cerámicas de cocina reducidas respecto a otras producciones como las vajillas finas de importación (Coll, Roig, Molina, 1997, 39 y 43).

\section{Contextos 450-500}

Interesante dada su situación geográfica es la ciudad de Iesso (Guissona, Segarra). El conjunto cerámico exhumado en sendos depósitos situados entre el cardo maximus y una de las domus, en el momento en que ambas estructuras ya no están en uso (al ser amortizadas por la construcción de una instalación vinícola), evidencia un panorama similar al observado hasta ahora en el resto de yacimientos, pero con una mayor notoriedad de la T. S. Hispánica (10\% de toda la vajilla). Al habitual cuenco de forma 37 tardía, del cual se documentaron siete individuos, cabe añadir un ejemplar del plato de forma 83b. En todo caso, de nuestras producciones la más destacada es la D.S.P., cuya presencia (44\%) es pareja a la de las importaciones africanas. Aporta en su variante reductora los platos Rigoir 1, 4 y 8, copas Rigoir 3b y 15, cuencos Rigoir 6a, 6b y 18 y mortero Rigoir 29; y en la oxidante, únicamente el plato Rigoir 1 (Uscatescu, 2004, 33-35). La formación de dichos depósitos se situaría en el siglo $\mathrm{V}$, con un terminus post quem aproximado del tercer cuarto del mismo (Uscatescu, 2004, 49). Sin mayor precisión, tal vez teniendo en cuenta algún otro depósito análogo (como el del Hospital de Santa Tecla, en Tarragona, bastante similar en su composición), podría pensarse en un momento del tercer cuarto del siglo $\mathrm{V}$ bastante avanzado. La falta de certidumbre sugiere sin embargo incluirlo en un amplio arco de la segunda mitad, en todo caso avanzada, del siglo $\mathrm{V}$.

También enmarcables en la segunda mitad del siglo $\mathrm{V}$ (y puede que en algún caso inicios del siguiente), unos silos y depósitos originalmente agrícolas del yacimiento de La Bastida (Rubí, Vallès Occidental) proporcionan, tal y como sucede en la mayoría de los yacimientos tardorromanos de la zona, una amplísima presencia de D.S.P. muy por encima de las pequeñas canti- dades detectadas de vasos africanos. Todos los fragmentos son de cocción reductora, en su mayoría procedentes del área provenzal. Entre ellos predominan los platos Rigoir 1, copas Rigoir 3 y los cuencos Rigoir 6 y 18, documentándose asimismo formas muy poco habituales como la jarra Rigoir 26b y el gran cuenco con vertedor Rigoir 36 (Bacaria et al., 2005, 180).

En Tarraco, en el nivel de amortización de la Torre de la "Antiga Audiència", con una cronología de la segunda mitad del siglo $\mathrm{V}$, se documenta el tipo Late Roman $C$ con la habitual forma Hayes 3C. Entre la D.S.P. gris y anaranjada, las formas que aparecen son el plato Rigoir 1 y el bol Rigoir 3. También comparece la T. S. Hispánica Tardía, en concreto el habitual bol carenado de forma 37 tardía (Aquilué, 1993a, 123 y 125).

\section{ConteXtos 475-525}

En otro de los estratos que amortizan el cardo maximus de Iluro (excavación C/ Sant Cristòfol 12, 89/90), contemporáneo o ligeramente posterior al del sector este del mismo (último cuarto del siglo V-primer tercio del siglo VI), se documenta D.S.P. (5,3\% de toda la vajilla tardía), mayoritariamente en su versión reductora. Entre éstas últimas dominan los cuencos y copas (50\% de los vasos sudgálicos): aparecen los platos Rigoir 1 y 8 , las copas Rigoir 3a, los cuencos Rigoir 6a, 6b y 18 y el plato-tapadera Rigoir 30. Entre las anaranjadas, lo hacen los platos Rigoir 1, los cuencos Rigoir $6 \mathrm{~b}$ y 18 y las copas Rigoir 15. Las producciones hispánicas tardías están únicamente representadas por el cuenco de forma 37 tardía y corresponden al 1,1 \% de toda la cerámica de mesa. Por último, se documentaría el borde del plato posible Hayes $9 \mathrm{~b}$ de la producción chipriota Late Roman D (0,66 \% del total de vajilla. Cela, Revilla, 2004, 52-53).

Disponemos de otros dos conjuntos significativos de la misma ciudad (pertenecientes a finales del siglo V-inicios de la siguiente centuria). El primero fue hallado en el segundo estrato de nivelación de la taberna mencionada anteriormente (excavación C/ Pujol 47, 1998). Entre el material exhumado: vajilla sudgálica gris, platos Rigoir 8 y cuencos Rigoir 18, así como algún fragmento informe de T. S. Hispánica Tardía (Cela, Revilla, 2004, 137). El segundo, procede de un potente relleno depositado sobre lo que había sido la cloaca del cardo maximus justo en la intersección con el decumanus maximus (excavación "El Carreró 43-45, 1981/82"). Aquí comparece de nuevo la producción D.S.P. gris (10 $\%$ de los vasos de vajilla tardía), representada por copas Rigoir 3 y cuencos Rigoir 18; así como la Terra Sigillata Hispánica Tardía, con el habitual bol carenado de forma 37 tardía (Cela, Revilla, 2004, 94).

No muy lejos, en el santuario de Can Modolell (Cabrera de Mar), diversos estratos de finales del siglo 

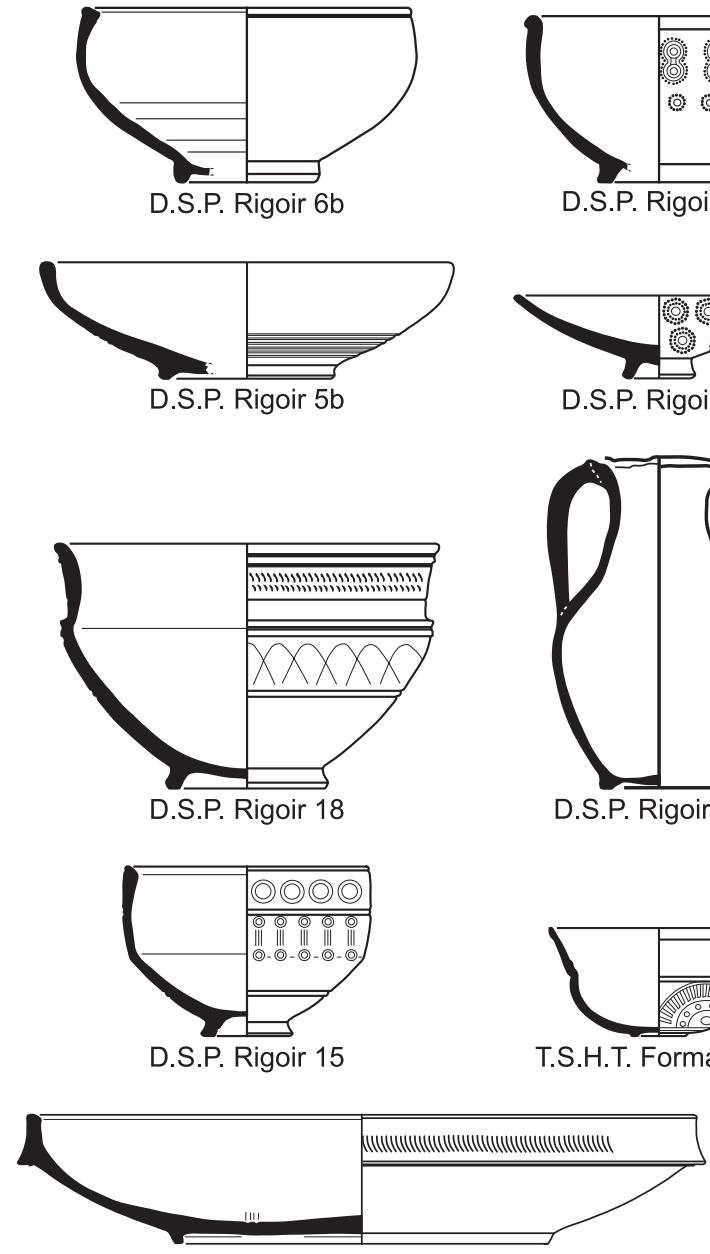

L.R."C" Hayes 3E

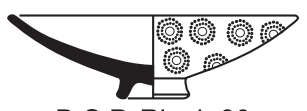

D.S.P. Rigoir 30
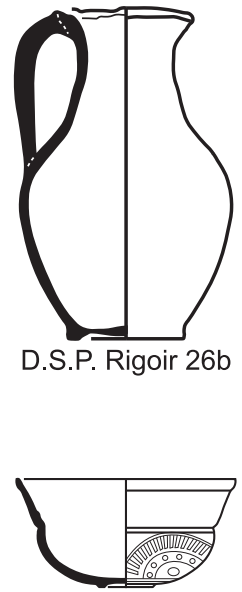

T.S.H.T. Forma $37 \mathrm{~T}$
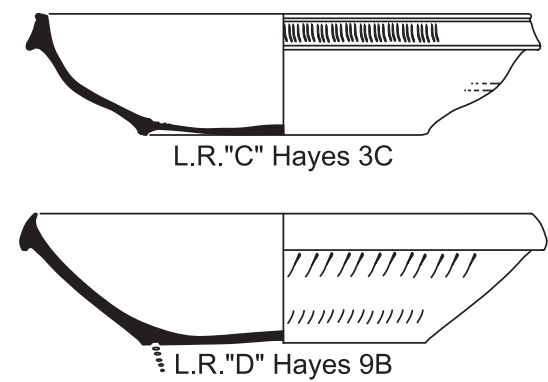

Contextos 475-500 (II)
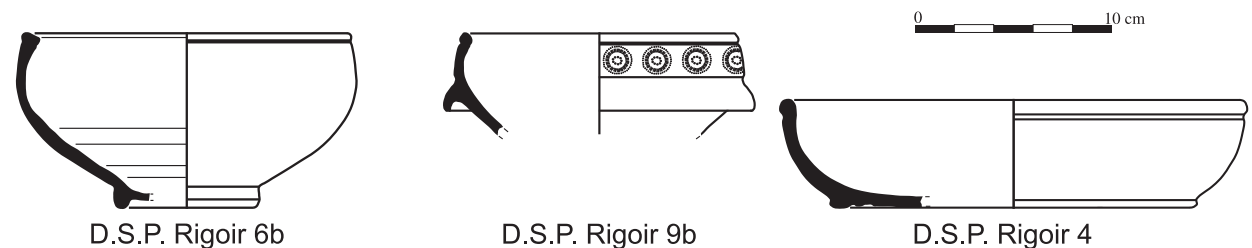

Contextos 500-525 (I)

Figura 4. Recapitulación de los contextos 475-500 y 500-525 a través de "formas-tipo" de las producciones analizadas. 
V-inicios del VI proporcionarían hipotéticamente piezas exóticas como el plato de vajilla chipriota Late Roman $D$ forma Hayes 2, aparte de aportar fragmentos de la habitual D.S.P.: platos Rigoir 1, copas Rigoir 2 o 3 y 15 (Clariana, Járrega, 1990, 337) y cuenco Rigoir 18 (Járrega, Clariana, 1996, 139-141).

\section{Contextos 500-525}

De finales del siglo V-primer tercio del siglo VI, en Iluro, un segundo estrato de nivelación en el sector oeste del cardo maximus proporcionó D.S.P. gris $(10,3 \%$ de la vajilla del conjunto), concretamente las copas Rigoir 3 a y el cubilete Rigoir 20 (Cela, Revilla, 2004, 75). Otro nivel de amortización del cardo maximus, situado ligeramente más hacia el norte (excavación "Recolzada del C/ Pujol 1987") y contemporáneo al anterior, documentó un repertorio más variado en lo referente a la vajilla sudgálica tardía. En la versión reductora (7 \% de la cerámica de mesa tardía), aparecieron platos Rigoir 1 y 4 , copas Rigoir 3a y 9b y los cuencos Rigoir 16 y 18 . No hay indicios de la variante oxidante, pero sí de la producción hispánica tardía, como es habitual plasmada en la presencia de los cuencos de forma 37 tardía (Cela, Revilla, 2004, 104). Un tercero, procedente de niveles de amortización de una ínsula del propio cardo y también más o menos contemporáneo (excavación C/ Pujol 43-45 1994), presentó únicamente D.S.P. anaranjada, concretamente un solo individuo: la copa Rigoir $6 \mathrm{~b}$ (Cela, Revilla, 2004, 126).

Otro contexto afín en los porcentajes al anterior, lo tenemos en Tarraco en la plaza de representación del foro (cerca de la escalera de acceso al recinto de culto de la terraza superior, excavación C/ Misser Sitges 812), en un momento de principios del siglo V. La gran mayoría de la vajilla fina corresponde como es habitual a la T. S. Africana Clara D, alcanzando cierta relevancia la producción sudgálica estampada tardía $(7,5 \%)$ y la sigillata focense, representada por los platos Hayes 3C (Remolà, 2000, 45).

\section{ConteXtos 525-550}

En este periodo (más bien avanzado), tenemos un estrato de obliteración en la carretera a Sant Martí d'Empúries. Sólo se documenta D.S.P., en concreto las formas Rigoir 4, 6, 9 y 18, reduciéndose de nuevo el porcentaje de su presencia respecto a las últimas importaciones finas africanas (8,32 \%. Llinàs, 1997, 160 y 164).

De aproximadamente mediados de este siglo VI, disponemos de otro ejemplo en el conjunto de fosas y silos tardorromanos del yacimiento de La Solana (Cubelles). Hay contextos cerrados desde finales del siglo III hasta de pleno siglo VII. En uno de pleno siglo VI (Barrasetas, Járrega, 1997, 132), se documentan diversos frag- mentos del plato de Late Roman $C$ forma Hayes 3 en sus variantes Hayes 3C y 3D (Barrasetas, 2001, 390). También en el mismo yacimiento, pero con menos precisión cronológica, han sido identificadas diversas formas de D.S.P. reductora. Se trata de los habituales platos Rigoir 1, así como de sus homólogos, hasta ahora inéditos, Rigoir 13/14 y la igualmente singular urna Rigoir 24b (Barrasetas, Járrega, 2004, 725).

\section{Contextos 500-550}

En estructuras constructivas documentadas en la Plaça Petita de Sant Martí d'Empúries, con una cronología de primera mitad del S.VI, aparece un único ejemplar de D.S.P. gris, forma Rigoir 18 (Aquilué, Burés, 1999, 393).

En Iesso, los niveles de destrucción que amortizan el complejo dedicado a la producción vinícola, ya sólo aportan en este periodo un ejemplar de vajilla sudgálica tardía gris, concretamente la copa Rigoir 3a (Uscatescu, 2004, 43). No se documenta ningún fragmento de vajilla hispánica.

De la misma cronología, otro contexto procedente de la plaza de representación del foro provincial de Tarraco (excavación C/ Merceria 11) aportó, dentro un pequeño porcentaje de vajilla fina, un ejemplo del plato Hayes 3B de Late Roman C (Remolà, 2000, 43).

Un cuarto ejemplo, lo hallaríamos en la sede del Colegio de Arquitectos de Tarragona, en la zona exterior de la plaza del recinto de culto. En un nivel en principio datado c. 475-525 (Aquilué, 1993b), cuya cronología fue posteriormente revisada y situada en la primera mitad del siglo VI (Remolà, 2000, 79), hay ejemplares de D.S.P. tanto oxidante como reductora (cuencos Rigoir 3 y 6); de T.S. Hispánica Tardía de la Meseta, forma 37 tardía; y un único fragmento de Late Roman C (Aquilué, 1993b, 109 y 114).

\section{ConteXtos 550-575}

Para este periodo disponemos de los estratos de nivelación que inutilizan las estructuras anteriores de la Plaça Petita de Sant Martí d'Empúries. En éstos se documenta el plato Rigoir 1 de D.S.P. gris (Aquilué, Burés, 1999, 394), así como el plato Hayes 3 de la vajilla focense Late Roman C (Aquilué, 1997, 89).

En Iluro, a mediados del siglo VI o segunda mitad del mismo puede datarse otro conjunto procedente del relleno de una gran fosa excavada en los niveles altoimperiales de una de las insulae situadas al oeste del cardo máximo (excavación C/ M. Villalonga 8-12, 99/2000). Entre el material exhumado se constata la importante presencia de D.S.P. gris (8 \% de la vajilla tardía presente en este nivel), concretamente de los platos Rigoir 1 y 8 (Cela, Revilla, 2004, 242). 


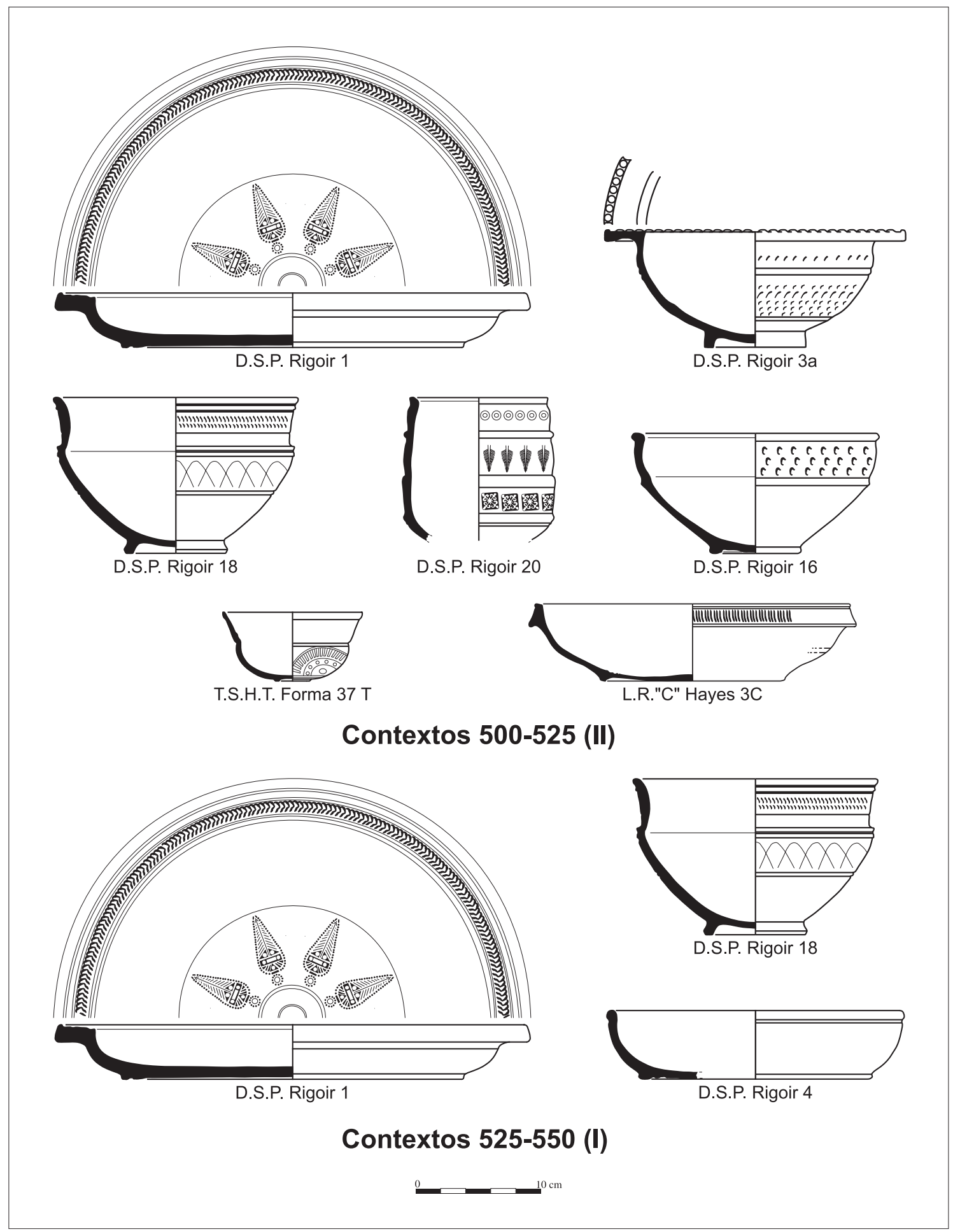

Figura 5. Recapitulación de los contextos 500-525 y 525-550 a través de "formas-tipo" de las producciones analizadas. 
Aún hay ejemplos de D.S.P. más allá del ecuador de dicho siglo. Una prueba la tenemos en los niveles tardíos de la plaza Font i Cussó, en Baetulo. En un contexto de la segunda mitad no muy avanzada del siglo VI se documenta únicamente la D.S.P. en una proporción del $5 \%$ respecto a la totalidad de los vasos finos de mesa: se trata del plato Rigoir 1 y la copa Rigoir 9. Otras producciones, como la T. S. Hispánica Tardía, están totalmente ausentes (Comas, Padrós, 1997, 122). Sin embargo, dicha cronología ha sido puesta en duda al apuntarse la posibilidad de que este conjunto fuera posterior: si bien se dataría como mínimo en la segunda mitad del siglo VI, en base al resto del material podría ser situado a finales del mismo o principios del siguiente (Járrega, 2000, 475).

\section{ConteXtos 575-600}

Y todavía tenemos alguna de nuestras producciones cerca del final del siglo VI. En este sentido se detecta una importante presencia de fragmentos de Late Roman $C$ tomados como fósil director de la última fase de ocupación de una factoría de salazones en la Ciutadella de Roses. Su presencia se reduce de nuevo a la forma Hayes 3, variantes Hayes 3C, posible Hayes 3D, Hayes 3H (Járrega, 1992, 1425) y Hayes 3E (Nieto, 1993, 202), las cuales datarían el abandono de dicho edificio aproximadamente en el último cuarto del siglo VI ${ }^{14}$. Ello ha de relacionarse también con el abandono a nivel habitacional del núcleo urbano situado en este mismo enclave y su posterior conversión en necrópolis a finales del siglo VI o inicios de la siguiente centuria: en los niveles de amortización de dicho hábitat apareció un nuevo plato (Hayes 5B) de la producción focense Late Roman C (Puig, 1998, 178).

Contemporáneo o ligeramente más moderno sería el relleno de un silo hallado en la plaza mayor de Sant Martí d'Empúries, cuya evidencia material lo data a finales del siglo VI o, tal vez, incluso a inicios del siglo VII. Aparte de algunos fragmentos bastante tardíos de T. S. Africana Clara D, se halló uno de D.S.P. anaranjada (probablemente por tanto, residual), concretamente la forma Rigoir 6 (Aquilué, Burés, 1999, 395).

De segunda mitad o finales del siglo VI, disponemos de un nuevo ejemplo en unos niveles de regularización, al pie de la grada, que elevan la cota de la arena del circo de Tarraco (excavación Plaça dels Sedassos). Dentro del

${ }^{14}$ Esta cuestión fue objeto de debate. En un principio, J. M. Nolla sitúa el abandono de la factoría en la segunda mitad del siglo VI, concretamente durante el reinado de Leovigildo (568586. Nolla, 1984, 477-478). Con posterioridad, X. Nieto piensa en un momento anterior, de primera mitad del mismo (Nieto, 1993, 204). Finalmente R. Járrega, propone rebajar de nuevo la cronología hasta finales del siglo VI (Járrega, 2000, 473). lote cerámico recuperado se constata la presencia, todavía, de un plato Hayes $3 \mathrm{C}$ de la vajilla Late Roman $C$ (Remolà, 2000, 75).

\section{Contextos 600-625}

Las únicas evidencias de la presencia de alguna de las producciones aquí estudiadas durante el primer cuarto del siglo VII proceden de Iluro, en concreto de una serie de fosas y silos (amortizados y convertidos en vertederos) excavados casi simultáneamente entre finales del siglo VI y, más probablemente, el primer tercio del siglo VII (excavaciones "El Carreró 49, 1997" y "C/ de la Palma 15, 2000"). Entre los diversos fragmentos cerámicos destaca la relevante presencia de la producción sudgálica estampada D.S.P. en versión reductora, con los platos Rigoir 1, copas Rigoir 3a y cuencos Rigoir 6a, 18 y 35. Asimismo y en menor número, de las copas Rigoir 15a y cuencos Rigoir 18 en la versión oxidante. Los porcentajes de ambas categorías, respecto al resto de vasos de mesa tardíos, serían bastante relevantes dada la cronología $(6,7$ $\%)$. Cabe añadir también la presencia de los cuencos de forma 37 tardía de T. S. Hispánica Tardía (Cela, Revilla, 2004, 215-217; 253-254). Sin embargo, la mayor parte de los citados fragmentos serían pequeños, estando además bastante erosionados. Esto y el hecho de que su presencia en un momento tan avanzado plantee ciertos problemas cronológicos, ha llevado a los propios excavadores a interpretarlos como residuales (Cela, Revilla, 2004, 361).

\section{ConteXtos DE TODO EL SIGLO VII}

El siglo VII parece corresponderse con el momento en el que cesan definitivamente las importaciones de vajillas de tradición romana. Del mismo modo que las africanas, no documentadas a partir de mediados de este siglo (Aquilué, 1998, 15), las orientales, que habrían competido con éstas tras la decadencia de las producciones sudgálicas estampadas, también dejan de llegar. Se detecta una sustitución progresiva de las vajillas de mesa y cocina por productos de factura mucho menos cuidada, fabricados a torno lento o a mano bajo atmósferas reductoras y con un limitado repertorio tipológico (básicamente recipientes de cocina, sobre todo ollas, o cazuelas bajas y cuencos en menor medida. Macias, 1999, 264; Aquilué, 2003, 17).

La evidencia material del periodo así lo indica. Por ejemplo, en establecimientos característicamente visigodos como el Puig de las Muralles (Puig Rom, Roses), en cronologías de inicios del siglo VII ${ }^{15}$ se documentaron distintas ánforas africanas y un único ejemplar de

\footnotetext{
${ }^{15}$ Para este yacimiento fue también sugerida una datación posterior, de mediados o segunda mitad del siglo VII (Járrega, 2000, 474).
} 


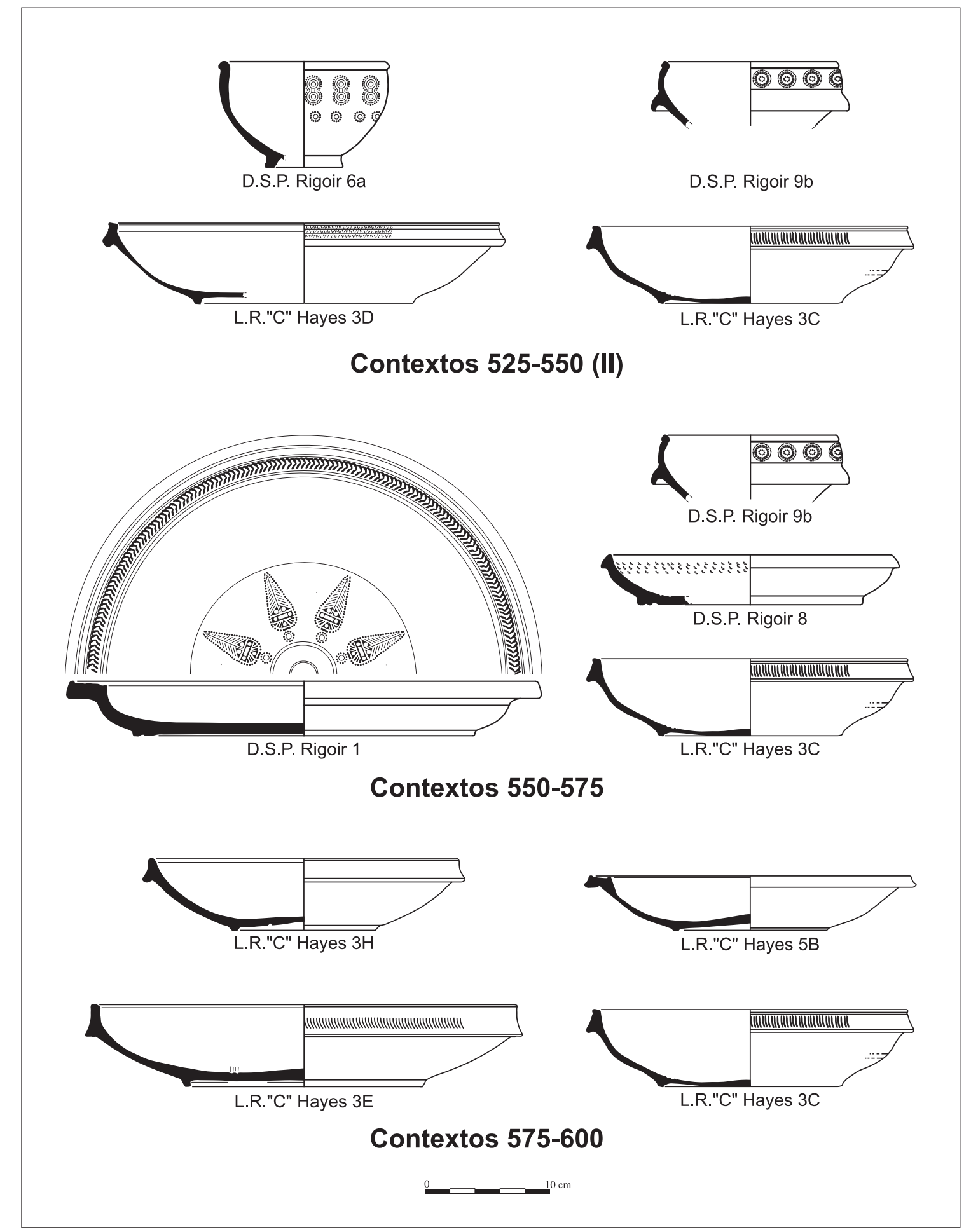

Figura 6. Recapitulación de los contextos 525-550, 550-575 y 575-600 a través de "formas-tipo" de las producciones analizadas. 
vajilla importada, un fragmento de T. S. Africana Clara D. El resto del material cerámico exhumado corresponde a ollas reductoras toscas o cerámica común oxidada (Nolla, Casas, 1997, 9-11). En un punto cercano, el yacimiento descubierto tras las obras de la carretera a Sant Martí d'Empúries, su última fase corresponde al relleno superior de un pozo de cronología avanzada (pleno siglo VII). Se hallaron pocas importaciones (T. S. Africana Clara D), con total ausencia de Late Roman “ $C$ " o " $D$ " (Llinàs, 1997, 162). E incluso en el mismo núcleo tardío de Sant Martí d'Empúries, en su plaza mayor, los rellenos de los silos de los momentos más tardíos (siglo VII bastante avanzado) documentan formas de T. S. Africana Clara D y ánforas datables en la segunda mitad del siglo, con total ausencia de los tipos aquí estudiados e importante presencia de ollas "groseras" de cocina (Aquilué, Burés, 1999, 396). Como puede apreciarse, la ausencia de las vajillas orientales es total; la excepción, muy puntual, sería la hipotética aparición de Sigillata Egipcia C, que recordemos se produce sólo durante este siglo, en el yacimiento de Els Vinyets (Vila-Rodona, Alt Camp). Se trataría en concreto del plato Hayes, 1972, fig. 89 b (Járrega, 1992, 1428). Ya hemos comentado la problemática identificación de estas piezas fuera de su lugar de origen.

Los contextos de los yacimientos del interior evidencian en este siglo únicamente cerámicas comunes reductoras: entre otros, hábitats rurales de Can Paleta (Lopez Mullor et al., 2003, 53) y Vilaclara (Enrich, Enrich, Pedraza, 1995, 84-85), ambos en Castellfollit del Boix (Bages); silos tardíos de la Església Vella de Sant Menna (Sentmenat) y de la villa de l'Aiguacit (Terrassa), en el Vallès (Coll, Roig, Molina, 1997, 40-43); o de la iglesia de Sant Vicenç de Rus (Castellar de n’Hug, Berguedà. López Mullor, Fierro, Caixal, 1997, 66).

Diversos ejemplos en Mataró y Tarragona también corroboran el dato. En Iluro, los rellenos de las fosas datadas en el primer tercio del siglo VII presentan un abrumador predominio de cerámicas culinarias (Cela, Revilla, 2004, 370). En Tarraco, la presencia mayoritaria es de los tipos comunes y en menor medida de T. S. Africana Clara D en sus formas más tardías. En contextos como los de Vila-roma IV o Plaça del Pallol (datación c. 600-713), Plaça de Sant Miquel o Plaça dels Àngels 1990 III (c. 575-713), C/ del Compte 12-14 III (c. 600-650), IV y V (c. 600-650/713. Macias, 1999, 191-258), mausoleo de la C/ de Sant Auguri (c. 600-650/713, con un escaso $2 \%$ de vajilla) y PERI 2-22b2 (c. 650-713, total ausencia. Macias, Remolà, 2005, 129) la tendencia es ésta y sin duda nos estamos acercando a la realidad cerámica que caracterizará a la alta Edad Media.

Incidiremos en ello en las conclusiones, donde veremos si esta dinámica de cambio en las diferentes categorías cerámicas y en sus repertorios formales implica también una transformación en la funcionalidad de los vasos documentados a partir de este momento. También si se pudiera relacionar ello con el advenimiento de una nueva cultura en la preparación y consumo de los alimentos.

\section{EVIDENCIAS DESCONTEXTUALIZADAS O DE DATACIÓN} AMPLIA

Incluimos aquí ejemplos de materiales de datación imprecisa, ya sea por proceder de excavaciones antiguas, o simplemente por no haberse dado los elementos necesarios para su adscripción a un marco temporal concreto ${ }^{16}$. Comenzando por el Pirineo, en el castellum de Roc d'Enclar (Sant Vicenç d'Enclar, Andorra), niveles datados aproximadamente en el siglo $\mathrm{V}$ documentan exclusivamente la producción sudgálica estampada D.S.P., tanto gris, platos Rigoir 1, copas Rigoir 3 y 9 y cuencos Rigoir 6 y 18; como oxidada, concretamente sólo la jarra Rigoir 27 (Yañez, 1997, 256-268).

En la zona noreste tenemos el importante yacimiento del Camp de la Gruta (Torroella de Montgri, Baix Empordà). En una cisterna perteneciente a esta villa rural (que va desde la República tardía hasta el siglo VI) hay evidencias de la producción sudgálica estampada D.S.P., formas Rigoir 1, 9, 12 y una posible Rigoir 6c (Nolla, Puertas, 1988, 37-40). También, de Late Roman C: platos Hayes 3B y 3E (Járrega, 1992, 1425-1426).

En la zona costera central, en la villa bajoimperial de Torre Llauder (Mataró), un conjunto de materiales descontextualizados evidenció la presencia de D.S.P. grises, formas Rigoir 1, 6, 6a, 9b, 15 y 18; y anaranjadas, formas Rigoir 1 y 18; también de T. S. Hispánica Tardía de la forma 37 tardía. En zonas de la pars urbana de la misma, se documentan asimismo D.S.P. grises formas Rigoir 1 y 18. Y en un vertedero, se exhumaron una copa forma Rigoir 15 de D.S.P. gris así como un cuenco de forma 37 tardía de T. S. Hispánica Tardía (Clariana, Járrega, 1994, 259-262).

También en el área rural de Iluro, algunas villae aportaron evidencias de los tipos estudiados. Excavaciones antiguas en la villa de Can Garí (Argentona, Maresme) no arrojaron a la luz demasiados materiales cerámicos. Entre ellos, sin embargo, destaca la aparición de una copa Rigoir 2 de la producción D.S.P. en variante reductora (Prevosti, 1981b, 247). El nivel de abandono de la villa de Els Caputxins (Mataró), datado ampliamente entre los siglos IV y V, documentó D.S.P. gris, concretamente una copa Rigoir 15 y los cuencos Rigoir 18 y 35 (Prevosti, 1981b, 376). Asimismo en la villa de Can Rafart (Mataró), excavaciones antiguas exhumaron al menos un cuenco de forma 37 tardía de T. S. Hispánica Tardía (Prevosti, 1981b, 347).

\footnotetext{
${ }^{16}$ No se incluyen por tanto en las láminas de "formas-tipo" por cuarto de siglo.
} 
Limítrofe con la anterior, el área rural de Baetulo documenta también algunos fragmentos. En la villa de Can Sentromà (Tiana, Maresme), niveles datados entre los siglos IV y V proporcionaron escasa D.S.P., en concreto diversos fragmentos de copas Rigoir 3 tanto en versión reductora (Guitart, 1970, 154 y 159), como oxidante (Caballero, 1972, 216). Tampoco, aunque presentes, fueron demasiado numerosos los de T. S. Hispánica Tardía, hallándose alguna forma 37 tardía (Guitart, 1970, 150). Muy cercana a Baetulo, la villa de Can Riviere (Badalona), a través de excavaciones antiguas, aporta al menos una decena de bordes de cuencos de forma 37 tardía junto con uno de la forma Ritterling 8 tardía de T. S. Hispánica Tardía (Prevosti, 1981a, 347).

Un punto que no ha sido muy citado en este trabajo es Barcino, donde la propia idiosincrasia de las excavaciones urbanas de urgencia sólo en pocas ocasiones ha permitido llegar a contextos claros bien datados (sobre todo por la gran dificultad de acceso a la información obtenida). Sin embargo, es una ciudad a la que lógicamente llegan estas producciones, como los fragmentos sin contexto procedentes del Museu d'Història de la Ciutat que demuestran la presencia de D.S.P. con las formas Rigoir 1, 6, 18 y otras indeterminadas (Bourgeois, 1970, passim), aparte de constatarse las Rigoir 4 (Plaça del Rei, Tinell...), Rigoir 6a (Tinell), Rigoir 15 (Plaça del Rei y Tinell) y Rigoir 9b, 23 y 36 (Plaça del Rei. Járrega, 1992, 1428-1440). Respecto a la aparición de Late Roman C y T. S. Hispánica Tardía, de la primera hay evidencias de la forma Hayes 3B en el Tinell y de la Hayes 3F en Santa María del Mar (Járrega, 1992, 1425-1426); de la segunda, de las formas 37 tardía y Ritterling 8 tardía (Járrega, 1992, 1450).

En el área rural de Barcino disponemos también de algunos ejemplos. Un conjunto de materiales descontextualizados procedentes de una excavación de urgencia en la villa de Can Bosch de Basea (Terrassa), datada desde época altoimperial hasta mediados o finales del siglo V, proporcionó sendos vasos de D.S.P. anaranjada, en concreto la copa Rigoir 3 y bol Rigoir 18, junto con otro en variante reductora, el cuenco Rigoir 6a. También de T. S. Hispánica Tardía, forma 37 tardía (Morral, Nuix, Martín, 1980, 20-24).

Más hacia del interior, ya en el ámbito rural, el grupo humano del pequeño taller siderometalúrgico de Cal Sanador (Òdena, Anoia), en un momento impreciso de los siglos IV-V, utilizaba vajilla sudgálica estampada gris, platos Rigoir 1 y 8 y copas Rigoir 2 ó 3; e hispánica, cuencos de forma 37 tardía (Enrich, Enrich, 1997, 22).

La villa de El Capell (Cervera), en niveles de todo el siglo $\mathrm{V}$ e inicios del siguiente, aporta un abundante lote de vasos de vajilla sudgálica tardía. Son minoritarios tanto los fragmentos de D.S.P. anaranjada, identificándose únicamente una copa Rigoir 15 y un bol Rigoir 18, como los de T. S. Hispánica Tardía, cuyas evidencias son el cuenco de forma 37 tardía y el plato de forma 83 (Nadal, Serra, 2003, 398). En cambio, la producción D.S.P. gris está ampliamente representada con las formas Rigoir 1, 2, 4, 5b, 6a, 6b, 8, 15, 16, 18 y 23 (Nadal, Serra, 2003, 394-396). Destaca la comparecencia de un vaso hasta ahora inédito, una cantimplora completa cocida en atmósfera reductora y con decoración estampada (en la zona del pitorro) definida provisionalmente como forma "Capell 1" (Nadal, Serra, 2003, 397). No hay constancia de su existencia en los centros productores y áreas de distribución inmediata de esta vajilla, por lo que, a falta de confirmación a través de análisis arqueométricos de su pertenencia al repertorio de las diferentes producciones de D.S.P., convendría considerar esta novedad con cierta cautela.

En el extremo occidental de este estudio se observa una afluencia dispar de estos vasos. La villa del Tossal del Moro (Corbins, Segrià) sólo documenta escasos fragmentos descontextualizados de T. S. Hispánica Tardía, de los cuencos de forma 37 tardía y Ritterling 8 tardía, y de D.S.P., de la forma Rigoir 1 (Revilla, Marí, 2003, 352). Por el contrario, en la cueva de La Colomera (Sant Esteve de la Sagra, Pallars Jussà), una serie de piezas recogidas en superficie proporcionó numerosos ejemplares de ambos tipos de vajilla. Las formas de D.S.P. gris son variadas: Rigoir 3a, 4, 6b, 8, 15 y 18; no tanto las anaranjadas, reducidas a la presencia del plato Rigoir 8. La T. S. Hispánica Tardía estaría representada por diversos fragmentos, lisos y decorados, de cuencos de forma 37 tardía (Padró, De la Vega, 1989, 14-15).

Finalmente, incluimos un lote de materiales sin contexto procedente de la villa de Casa Blanca (Jesús-Tortosa, Baix Ebre). Resultan de interés debido a la preeminencia en el conjunto de la vajilla hispánica $(14,12 \%$ de la vajilla tardía recogida), así como por su aportación de formas casi inéditas en el noreste: junto con las habituales Ritterling 8 y forma 37 tardía, que dominan de forma abrumadora, se documentaron también sendos ejemplares del gran cuenco de forma 42 y de la jarra de forma 85 (Pérez Suñé, 2003, 180-182). Hay asimismo constancia de la producción sudgálica estampada D.S.P., representada en su versión gris por los platos Rigoir 1 y en la anaranjada por los cuencos Rigoir 6b y copas Rigoir 15 . Por último, se documentan diversos fragmentos de los platos Hayes 3 de Late Roman C (Pérez Suñé, 2003, 226-229).

COMPARATIVA CON EVIDENCIAS EN CIUDADES CERCANAS SITUADAS FUERA DEL MARCO GEOGRÁFICO DEL ESTUDIO

Nos referimos en primer lugar a Caesaraugusta. Veremos cómo en ésta la preponderancia, al igual que en todo el valle central del Ebro, corresponde a la vajilla fina hispánica. En la costa levantina, en cambio, se observan dinámicas diferenciadas. En Valentia, la recep- 


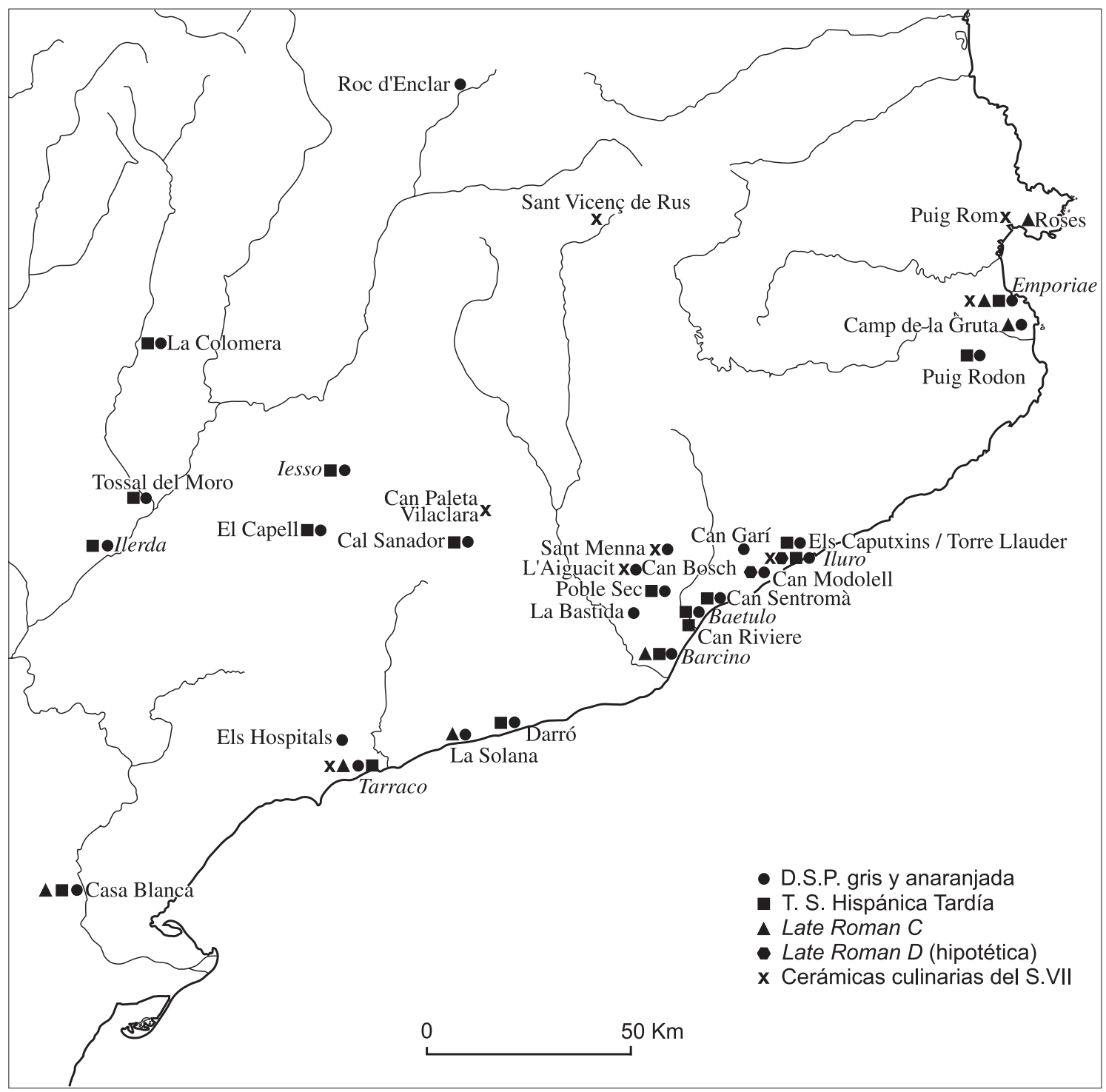

Figura 7. Principales yacimientos mencionados en el texto que documentan los tipos cerámicos analizados en los siglos V-VII.

ción de importaciones galas y de las producciones hispánicas tardías es bastante pareja. En Lucentum y, más hacia el sur, en Carthago Spartaria, la mayor relevancia, en lo que se refiere a las clases cerámicas analizadas, corresponde a las vajillas orientales.

Comenzando por el interior, Caesaraugusta, capital del conventus que lleva su nombre, manifiesta, como el resto de su demarcación territorial, la absoluta primacía de la T. S. Hispánica Tardía sobre cualquier otra producción de vajilla fina (incluyendo a las africanas), junto con una gran diversificación de formas. Dos contextos pertenecientes al periodo que nos interesa así lo indican.
El primero, de pleno siglo V, corresponde a excavaciones realizadas en la orchestra del teatro romano. En este punto, un potente nivel arrojó un elevado número de piezas de vajilla hispánica, entre las cuales predominaban de manera aplastante los cuencos Ritterling 8 tardía y forma 37 tardía (tanto lisos como decorados), por encima de otros vasos menos representados como el bol o copa de forma 5, la botella de forma 12, el gran cuenco de forma 42, o los platos Dragendorff $15 / 17$ y formas 6 , 74 y 82. En la gran mayoría de los casos, como sucederá en el contexto que veremos a continuación, las piezas de vajilla hispánica proceden de los alfares riojanos. 
Llegan también individuos fabricados en la Meseta, pero en mucha menor cantidad y con poca diversificación formal. Respecto a otros tipos de vajilla, la D.S.P. gris es escasa, quedando reducida a la presencia de sendos fragmentos de las formas Rigoir 3a y 15 (Paz, 1991, 29). El segundo contexto, también urbano (solar entre las C/ Gavín y Sepulcro), presenta dos niveles diferenciados. En el inferior, que corresponde a estratos de nivelación del hábitat datado entre c. 460-480, queda patente la superioridad de fragmentos recuperados de $\mathrm{T}$. S. Hispánica Tardía frente a otras clases de vajilla. De nuevo el cuenco Ritterling 8 tardía es el vaso de mayor presencia, por encima de la forma 37 tardía a mucha distancia del resto de los formas, caso del bol o copa de forma 5 , de las botellas de formas 12 y 20 , de la urna de forma 14, del gran cuenco de forma 42, de la olpe de forma 85 , o de los platos Dragendorff $15 / 17$ y formas 6 , 80 y 83. La vajilla gris sudgálica D.S.P., prácticamente testimonial, ofrece una posible copa Rigoir 6 y un plato Rigoir 8. Es también el único estrato que documenta fragmentos de vajillas orientales Late Roman $C$, al menos uno atribuible al habitual plato Hayes 3 (Paz, 1991, 26-27). El nivel superior, un estrato de abandono de las estructuras de hábitat construidas sobre el aterrazamiento anterior, datado a finales del siglo $\mathrm{V}$ o inicios del VI, presenta una dinámica bastante similar: clara supremacía del cuenco Ritterling 8 tardío y algo menos de la forma 37 tardía en lo referente a vajillas hispánicas. Los otros vasos atribuibles a esta clase son el bol o copa de forma 5, los platos Dragendorff 36 tardío y formas 6 y 83, el gran cuenco cerrado de forma 42, la cazuela Dragendorff 44, la botella de forma 14 y una posible olpe de forma 85 . Son también muy minoritarios los fragmentos de D.S.P. gris, apenas una decena, entre los cuales se diferenciaron un plato Rigoir 1, una posible copa Rigoir 3 y un cuenco Rigoir 18 (Paz, 1991, 27).

En la costa levantina, la ciudad de Valentia nos ofrece contextos bien datados en los cuales se advierte la presencia de casi todas las categorías cerámicas que estudiamos. Como establecimiento portuario recibe, aparte de las habituales africanas, tanto las producciones galas como las orientales, también incluso las hispánicas, como hemos visto mucho menos habituales en los enclaves costeros catalanes. Dentro del siglo V, un contexto de la primera mitad del mismo, procedente del solar de la antigua Almoina, documentó la presencia de las D.S.P. sudgálicas (plato Rigoir 4, cuenco Rigoir 18 y mortero Rigoir 29); así como de la oriental Late Roman C (plato Hayes 3. Pascual, Ribera, Rosselló, 2003, 70). Ligeramente posteriores son los contextos comprendidos entre el segundo y tercer cuarto del mismo, con sigillatas hispánicas tardías, concretamente los cuencos Ritterling 8 tardío y forma 37 tardía, así como con una única evidencia de vajilla sudgálica tardía gris (cuenco Rigoir 15). Más adelante, en contextos de inicios del siglo VI (en la misma zona de L'Al- moina y en unas fosas bajo el Palau de les Corts Valencianes), aparece una mayor diversificación en ambas categorías: las formas de la T. S. Hispánica Tardía son los cuencos Ritterling 8 tardío, la forma 37 tardía y la pátera Dragendorff 36 tardía; las de la vajilla D.S.P., la pátera Rigoir 1, la copa Rigoir 7 y el bol Rigoir 18. De pleno siglo VI, unos rellenos sobre una necrópolis en la zona de L'Almoina evidenciaron la presencia de un ejemplar de vajilla de la Meseta, de nuevo el cuenco Ritterling 8 tardío (Pascual et al., 1997, 181-182). Los últimos momentos en los que se documentan estas vajillas corresponden al último cuarto del siglo VI, que tal vez pudiera dilatarse hasta inicios de la centuria siguiente. En los niveles de amortización del circo, en la excavación de la C/ del Mar 19 y en la zona de Banys de l'Almirall, están presentes las D.S.P. (plato Rigoir 1, copas Rigoir 2, 5b y 9a, cuencos Rigoir 18 y 19); la T. S. Hispánica Tardía (bol de forma 37 tardía); las Late Roman C (platos Hayes 3B, 3D y 3H); e incluso la Late Roman D o sigillata chipriota tardía (platos Hayes 2 y 9C. Pascual et al., 1997, 182-185). Alguna de estas últimas evidencias sería residual, al menos en lo que se refiere a la vajilla estampada sudgálica (Pascual, Ribera, Rosselló, 2003, 92) y, con toda seguridad, a la hispánica. Con posterioridad al primer cuarto del S.VII, ya no se documentará ninguna de estas clases cerámicas.

Siguiendo hacia el sur de la costa levantina, uno de los yacimientos mejor estudiados de época tardorromana es el de Lucentum, situado en el actual barrio de Benalúa, en el corazón de la capital alicantina. En esta ciudad, un prolífico depósito aportó diversos materiales que conforman un contexto bien datado en el último cuarto avanzado del siglo VI (Reynolds, 1995, 203). En él, abundaban los fragmentos de cerámica fina, sobre todo atribuibles a producciones africanas, que constituían un $88 \%$ de todos los vasos de mesa. El resto correspondió a las vajillas orientales, entre las cuales destacaba sobremanera $(9,9 \%$ del total) la cuantiosa presencia de los platos Hayes 3 de la producción focense Late Roman C. Más de la mitad de los ejemplares se relacionaron con la variante Hayes 3F, aflorando también en semejantes cantidades algunos de los tipos Hayes 3C, $3 \mathrm{D}$ y $3 \mathrm{E}$, algo más del Hayes $3 \mathrm{G}$ y un posible Hayes $3 \mathrm{H}$. Aparte, se documentó un solo fragmento asociado a la forma Hayes 6 y otro al plato tardío Hayes 10A. Otra producción de vajilla oriental, la chipriota Late Roman $D$, se halló asimismo representada $(1,08 \%)$ con dos o tres bordes del plato Hayes 2, tres del Hayes 5, uno del Hayes 9A y otro posible de la forma Hayes 9B (Reynolds, 1995, 196). Los exiguos fragmentos de D.S.P. gris presentes $(0,3 \%)$, a pesar de proceder de un conjunto de datación avanzada, podrían no ser residuales. Correspondientes a la urna Rigoir 24 y al mortero Rigoir 29, no sería descabellado relacionarlos con la producción tardía provenzal del siglo VII a la que aludió C. Raynaud (Raynaud, 1993, 411). 
Para finalizar el análisis comparativo, nos detenemos en un punto clave del comercio en el Mediterráneo occidental: el puerto y enclave mercantil de Carthago Spartaria. Para estos momentos tardíos, nos fijaremos en diversos contextos procedentes de la capital bizantina en Spania. Uno de los que arrojó un importante volumen de material cerámico corresponde a un edificio comercial construido sobre las ruinas de lo que había sido el teatro de la ciudad. La fase de fundación del mismo, con una datación de segundo cuarto avanzado o mediados del siglo V, proporcionó un solo fragmento de D.S.P. gris de origen provenzal perteneciente a la copa Rigoir 3 , que junto con la T. S. Lucente constituyen c. $6 \%$ del total de la vajilla importada siendo el resto T. S. Africana Clara D (Murcia et al. 2005, 5). No hay constancia de la comparecencia de vajillas hispánicas u orientales. Con posterioridad, la fase de abandono del citado inmueble, situada en la segunda mitad avanzada del siglo V o más bien primer cuarto del siguiente, no documenta fragmentos de ninguna de las producciones analizadas, sólo exclusivamente de cerámica fina africana (Murcia et al. 2005, 15). Y es que éstas parecen monopolizar el mercado durante el siglo VI en la antigua ciudad bárquida, momento en el cual desaparecen totalmente las vajillas hispánicas y sudgálicas que se documentaban, eso sí de forma muy esporádica, durante el siglo anterior. Sorprende también la nula representación en este recinto de la Late Roman C, lo que contrasta con la abundancia de las ánforas orientales (Ramallo, Ruiz Valderas, Berrocal, 1996, 153). Un último contexto de esta zona, posterior al edificio comercial y correspondiente a la fase de destrucción de la ciudad durante el primer tercio del siglo VII, tampoco presenta ningún fragmento de vajilla de procedencia oriental. Sí en cambio un importante volumen de T. S. Africana Clara D en claro retroceso frente a la cerámica tosca de producción local, que constituye más de un tercio de todos los individuos documentados (Ramallo, Ruiz Valderas, Berrocal, 1997, 204).

Otro punto de la ciudad sí que muestra un importante conjunto de vasos de vajillas orientales. Excavaciones en la actual Plaza de los Tres Reyes sacaron a la luz restos de hábitat de la ciudad tardorromana y bizantina. Entre los materiales recuperados abunda el lote de vasos de Late Roman $C$, circunscrito a la presencia de diversas versiones del plato Hayes 3. Destaca en número la cantidad de bordes adscritos al tipo Hayes $3 \mathrm{E}$, por encima de los de las variantes Hayes 3C, 3F y 3D respectivamente (Méndez, 1983-1984, 148-153). La recepción de todos ellos en este punto habría comenzado en el último cuarto del siglo $\mathrm{V}$ y perdurado hasta al menos finales de la siguiente centuria. Finalmente hay presencia de la vajilla chipriota Late Roman $D$ en forma de un fragmento perteneciente al plato Hayes 2 (Méndez, 1988, 148).

\section{CONCLUSIONES}

Hasta ahora hemos analizado diversos aspectos de la distribución y cronología de las producciones tardías sudgálicas, hispánicas y orientales, a la vez que enumerado los contextos en los que se constata su presencia desde inicios del siglo V. Hemos visto también el momento de aparición de aquellos vasos documentados desde ese instante. En estas conclusiones además, culminando nuestras pretensiones iniciales, nos aproximaremos a su final en el noreste peninsular, a la vez que hipotetizaremos sobre una de las posibles causas del cese de su llegada.

En primer lugar, hemos apreciado cómo la llegada de las vajillas hispánicas, a diferencia del valle del Ebro, es casi testimonial y bastante mayor en la costa que en el interior. Se observa además una relación inherente a las vías comerciales determinadas por el Ebro y sus afluentes, ya sea en la cuenca del mismo (área de Caesaraugusta, Ilerda o Iesso) o en su desembocadura: en nuestra zona, la presencia más relevante se produce en la villa de Casa Blanca, en el área de Dertosa, único punto en el cual estos productos hispanos se sitúan por encima de los narbonenses y provenzales. El repertorio tipológico es ciertamente muy poco diversificado, centrándose casi en exclusiva en el bol de forma 37 tardía, único vaso con una relativa salida en un mercado dominado por los tipos africanos. Los demás, comparecen de manera muy puntual. En cuanto a la cronología, corresponde básicamente al siglo $\mathrm{V}$ y la tendencia es que estos vasos no suelan perdurar en el siguiente. Los últimos ejemplos en nuestra zona los tenemos en contextos con un T.A.Q. c. 525, por tanto, podríamos pensar en los inicios del siglo VI, o como mucho en el primer cuarto del mismo, como momento final de su recepción.

Al contrario que la hispánica, la presencia de la vajilla sudgálica D.S.P. es ciertamente relevante en contextos de los yacimientos catalanes, ocupando en casi todos los casos (aunque con bastante diferencia) el segundo lugar en importancia tras la T. S. Africana Clara D. Y lo es tanto en diversificación de formas en el repertorio como en distribución geográfica, documentándose por igual en el litoral y en el interior (incluso en el área pirenaica), que es donde alcanzan mayores proporciones. De hecho, se ha hablado de un flujo ininterrumpido en su llegada, una continuidad en las relaciones comerciales por vía terrestre y marítima entre el noreste hispánico y la Galia meridional, constatada principalmente durante el siglo $\mathrm{V}$, que no cesaría tras el final de las producciones narbonenses: su lugar sería inmediatamente ocupado por las provenzales (a mediados de este mismo siglo), sin variación de dicha dinámica (Bacaria, 1993b, 344). Respecto al momento final de su llegada, la hipótesis más extendida lo sitúa en la primera mitad o a mediados del siglo VI (entre otros: Járrega, 2000, 468; 
Pascual, Ribera, Roselló, 2003, 92; Cela, Revilla, 2004, 361). Parece claro que se produce una progresiva rarefacción de los tipos sudgálicos durante esa primera mitad. Sin embargo, su presencia es aún relativamente notable en algunos contextos de la primera mitad y el tercer cuarto del siglo VI que en principio no nos sugieren residualidad (por ejemplo, en Tarraco, Iluro o Baetulo ${ }^{17}$ ). Debido a ello, se podría proponer una ligera modificación de esta idea: aún en exiguas cantidades, el final de su recepción, al menos en algunos enclaves litorales, podría situarse aproximadamente a mediados o incluso el tercer cuarto del siglo VI. A favor de esta afirmación aduciríamos la respetable proporción de los vasos sudgálicos en unos conjuntos que fueron datados con precisión. En contra, podría esgrimirse la opinión de algunos investigadores franceses sobre la degradación progresiva de la producción provenzal desde mediados del siglo VI, con el consiguiente empobrecimiento del repertorio y restricción de su distribución ya en la centuria siguiente (Raynaud, 1993a, 411; Bonifay, Rigoir, 1998, 370). Sea como fuere, cabría considerar el relevante papel que aún juegan estas vajillas provenzales en el noreste peninsular durante la primera mitad del siglo VI. El hallazgo futuro de nuevas evidencias en contextos del tercer cuarto o la segunda mitad del mismo ayudaría a corroborar nuestra hipótesis.

En el caso de las vajillas orientales, hay una gran diferencia en cuanto a la trascendencia de la vajilla focense y el resto. Tanto la Late Roman D chipriota como, incluso en mayor medida, la sigillata egipcia, no pasan de ser producciones documentadas de forma absolutamente excepcional, siendo su atribución insegura en alguno de los casos. De hecho, nos decantamos por no considerar la llegada de vajillas egipcias por las razones anteriormente expuestas y tal y como sugieren la mayoría de autores. Pueden asimismo rebatirse buena parte de los hallazgos hasta ahora señalados de vajilla chipriota, una producción que en las costas de la Península Ibérica sólo estaría presente en Lucentum en número superior a uno o dos ejemplares. No hay que descartar la posibilidad de que pudiera llegar algún vaso en momentos y lugares muy puntuales, de manera casual, probablemente acompañando a alguna ánfora, pero tampoco parece que se pueda afirmar su llegada sistemática. Por el contrario, los vasos focenses están convenientemente bien documentados, aunque sólo en áreas litorales o cercanas a la costa, mientras que las evidencias más interiores estarían relacionadas con el Ebro (villa de Casa Blanca o Caesaraugusta, fuera ya de nuestro ámbito de estudio).

\footnotetext{
${ }^{17}$ Esta última aún más si cabe de haber tenido en cuenta la revisión cronológica que sitúa el contexto en una datación más moderna.
}

La llegada más regular de la Late Roman $C$ se relacionó en un principio con una cierta decadencia de los talleres de claras africanas tras la implantación del reino vándalo en África en 429. Ello explicaría el auge en occidente de esta producción a partir de ese momento (entre otros: Gutiérrez, 1998, 557). Actualmente dicha teoría ha sido desestimada, hablándose de la intervención de varios factores, aparte de disponer del dato que indica cómo a inicios del siglo V había una gran demanda del servicio de mesa focense en Constantinopla, lo cual podría haber dado un impulso importante a la producción (Martin, 1998, 117). En el área analizada hay un único ejemplo de vajilla focense anterior al tercer cuarto del siglo V. La falta de certidumbre de dicha atribución hace que sea ésta la fecha aproximada a partir de la cual llegará con cierta asiduidad. Ello concuerda con el inicio de la exportación de este tipo cerámico hacia el Mediterráneo occidental, establecido a partir de mediados del siglo V (Reynolds, 1995, 35).

Para su momento final, se generó cierta controversia. Según X. Nieto (1984, 547), la irrupción bizantina en la costa sudeste habría producido alteraciones en las relaciones comerciales y tanto la recepción de este tipo como la de los africanos no se habría reemprendido tras la expulsión de los orientales en 624 por parte de Suintila. R. Méndez, que analizó este tipo en Carthago Spartaria (Méndez, 1983-1984, 156), determinó que las vajillas focenses habrían llegado durante el último cuarto del siglo $\mathrm{V}$, su gran momento sería la primera mitad del siguiente y su final, hacia inicios del siglo VII, una vez los visigodos expulsan a los bizantinos y arrasan la ciudad (también: Ramallo, Ruiz Valderas, Berrocal, 1997, 215). Estudios recientes han determinado un importante dinamismo comercial en la capital de una provincia imperial autónoma respecto a la del norte de África, traducido en una notable presencia de materiales importados (Murcia, Guillermo, 2003, 215). De este modo, se produciría en Cartagena una fluidez en los intercambios que conllevaría la llegada de vajillas africanas y orientales hasta el abandono de los ejércitos imperiales, un tráfico que no se documenta posteriormente, más que por este hecho, por el retraimiento del hábitat producido por una destrucción casi total.

Y es que para otros autores la ocupación bizantina no comportaría el cese de las importaciones en general, ya que se siguen documentando todos estos productos durante la segunda mitad del siglo VI. De hecho se ha pensado que, al igual que en Cartagena, la dominación imperial habría favorecido, tanto en el sudeste como en otros puntos litorales mediterráneos, un cierto auge o impulso económico en un momento en el que las zonas rurales del interior de la Península iban haciéndose cada vez más autosuficientes (Manzano, 2003, 549). Los contextos analizados en nuestra área de estudio evidencian la presencia de vasos focenses, en pequeñas cantidades, 
incluso dentro del último cuarto de siglo en algunos puntos del litoral. En este momento dichos enclaves documentan casi exclusivamente la forma Hayes 3, fabricada hasta el último cuarto o finales del siglo VI (Raynaud, 1993b, 503), cuando es sustituida por la Hayes 10 (Hayes, 1972, 343), cuyas variantes "A" y "B" son producidas a partir de ese mismo instante. De ésta última, disponemos de un ejemplar procedente de Centcelles (Járrega, 1992, 1425), que por tanto debe ser como mínimo contemporáneo a esa fecha ${ }^{18}$; mientras que de las anteriores, tanto en el área analizada como en el Levante peninsular, hay evidencias de los tipos tardíos Hayes 3F-H durante el último cuarto del siglo VI en la Ciutadella de Roses, Valentia, Carthago Spartaria y sobre todo en Lucentum, aparte de atestiguarse aún otras variantes (Hayes 3C-E) que en un principio deberían ser residuales pero que aún aparecen en relevantes cantidades. La idea generalizada sobre el cese de las exportaciones de la vajilla focense tardía hacia el Mediterráneo occidental sitúa éste a mediados del siglo VI (Martin, 1998, 118). De forma menos tajante, como mínimo se constata un descenso paulatino en su recepción en la segunda mitad del mismo (Reynolds, 1995, 36). Esta última hipótesis parece más acertada ya que, teniendo en cuenta los datos que acabamos de exponer, el final de la recepción de la Late Roman $C$ en nuestras costas, eso sí, en volúmenes ostensiblemente reducidos, podría establecerse entorno al último cuarto del siglo VI.

Así, su desaparición debería relacionarse con la dinámica de cese paulatino de las importaciones y cambio en la concepción del mobiliario cerámico más bien que con cualquier acontecimiento político como el del desembarco, establecimiento y posterior abandono bizantino del sudeste peninsular. Los contextos del siglo VII así lo indican. Aunque en un principio se trate de conceptos diferentes, lo cierto es que las vajillas de tradición romana pierden peso respecto a otro tipo de vasos, de factura tosca, fabricados a mano en entornos locales y cocidos en atmósferas reductoras, integrantes de un repertorio formal poco diversificado. Se trata de recipientes culinarios, que obviamente ya existían antes pero que ahora adquieren una nueva dimensión. Formas planas como los platos o la mayoría de recipientes de decantación para servicio o ingestión de líquidos tienden a desaparecer, ya que tampoco serán fabricados por las producciones locales de pasta grosera. Esta tendencia, como hemos visto bastante generalizada, ha sido interpretada, entre otras hipótesis, como parte de un proceso de transformación hacia una nueva sociedad y con ello una nueva cultura en la preparación de los alimen-

\footnotetext{
${ }^{18}$ Para esta forma sigue siendo aceptada la cronología propuesta por J. W. Hayes: c. 570-620 (Hayes, 1972, 346; 1980, 527; Raynaud, 1993b, 503; Reynolds, 1995, 147; Martin, 1998, 116).
}

tos, en su presentación en la mesa y en su consumo. Se produciría así un cambio en la dieta alimenticia, basada en productos autóctonos y con ello menos variada y elaborada, lo que a su vez demostraría síntomas de regresión de la producción agrícola en beneficio de la recolección, la caza y la ganadería (Aquilué, 2003, 18) ${ }^{19}$.

Ambos procesos, transformación social y nueva cultura culinaria, son ya valorados en términos de cultura material bajo una óptica que rechaza o como mínimo matiza la creencia tradicional de decadencia y economía autosuficiente sin más. El fenómeno de las producciones locales o regionales de factura grosera y la concentración tipológica de sus repertorios evidenciaría una realidad compleja que no debería ser interpretada únicamente como un rasgo más de esa autarquía o aislamiento cultural, pues respondería a estrategias regulares de adaptación a la situación del momento que, entre otras cosas, permitirían intercambios a pequeña escala. De este modo, los cambios que afectan a cada producción deberían ser explicados dentro del contexto global de transformación en las relaciones entre producción e intercambio (Cela, Revilla, 2004, 422) ${ }^{20}$.

No es objeto de nuestro análisis entrar a fondo en ese debate, pero efectivamente los mismos contextos aquí analizados, que también ponen de manifiesto una dinámica regresiva en la llegada de las vajillas y ánforas africanas hasta la determinante conquista musulmana de la provincia de África, evidencian asimismo una cierta diversificación en la procedencia de otros tipos cerámi-

\footnotetext{
${ }^{19}$ Algunos de estos cambios en la dieta habrían podido ser documentados por la Arqueología. Es el caso de Sant Martí d'Empúries, cuyos vertederos datados entre la segunda mitad del siglo VI y primera de la centuria siguiente constataron evidencias de recolección marina, de caza y pesca, así como la explotación de recursos procedentes de la ganadería. Pese a ello, los análisis de las inhumaciones tardorromanas documentadas en dicho enclave muestran cómo a partir de la segunda mitad del siglo VI la dieta principal, basada en los cereales, seguía siendo eminentemente vegetariana (Aquilué, Burés, 1999, 399). Ambas ideas se complementarían tendiendo en cuenta el esquema pensado para los siglos VI-VII: economía agrícola basada en la ganadería extensiva y trashumante, en detrimento de la agricultura romana tradicional de cereales, vid y olivo (Macias, 2003, 37).

${ }^{20}$ Todo ello como parte de un proceso complejo de reorganización que orientaría las estructuras productivas hacia la explotación de los recursos de un territorio de dimensiones reducidas (pero sin límites predeterminados, ya que permitiría los intercambios a pequeña escala). En ese contexto es en el que debería considerarse la aparición de la actividad alfarera regional, que respondería a necesidades todavía adecuadas a modelos de consumo antiguos. Los intercambios serían "periféricos", afectando a un menor número de objetos sin vinculación a ninguna gran red de intercambio (Cela, Revilla, 2004, 396). Este modelo explicativo para Iluro podría ser perfectamente extrapolable a otros enclaves.
} 
cos: durante un breve lapso temporal (segunda mitad del siglo VII) seguirán llegando importaciones, en este caso de cerámicas orientales comunes y de cocina fundamentalmente sirio-palestinas que irán reemplazando paulatinamente a sus homólogas centromediterráneas y del Egeo (que a su vez habían ido sustituyendo poco antes a las de cocina africana. Macias, Remolà, 2005, 128). Pero éstas no pasan de ser productos minoritarios recibidos en ciertos enclaves portuarios y en menores cantidades respecto a las centromediterráneas, documentadas en la primera mitad del siglo VII en un mayor número de puntos de la costa. Y es que también en el litoral se está consolidando un fenómeno, apreciable desde la segunda mitad o finales del siglo VI en el ámbito rural y al cual aludimos en todo momento: el peso fundamental será ejercido por las producciones locales o regionales especializadas en la fabricación de recipientes culinarios.

La reducción del repertorio a raíz de la desaparición de ciertos vasos comportaría a su vez la de las funciones culinarias asociadas a los mismos, el ejemplo estaría en la fuerte regresión de los morteros en este momento, lo que indicaría una simplificación en la transformación de los alimentos así como un menor protagonismo de los condimentos de origen agrícola. Como contrapartida, el predominio corresponderá a los recipientes empleados para cocinar directamente al fuego, caracterizados por amplias bocas, útiles para la introducción de sólidos cárnicos (Macias, 2003, 37). Así pues, toscos cuencos, ollas o cazuelas de base plana realizarían paulatinamente las funciones anteriormente desempeñadas por las vajillas, a modo de probable consumición directa de los alimentos preparados en ellas, mucho menos elaborados. No se trata de que estén asumiendo las labores anteriormente ejercidas por vasos específicos vinculados al concepto "vajilla de mesa", sino que los usos culinarios particulares de estos últimos dejan de existir y por tanto, ya no tienen razón de ser ante la presumible llegada de una nueva cultura de la alimentación.

No se trata en definitiva de menoscabar la intervención de factores políticos, económicos o comerciales, también en parte determinantes en el cambio de concepción del mobiliario cerámico (aspecto que no se puede poner en duda), sino más bien de poner el acento en las novedosas prácticas cotidianas, fruto de estrategias de adaptación espontáneas, de unas comunidades en proceso de transformación cuya dimensión se percibirá en la sociedad de la alta Edad Media.

\section{BIBLIOGRAFÍA}

AQUILUÉ, X., 1993a: "Las cerámicas finas de los niveles tardorromanos", La "Antiga Audiència". Un acceso al foro provincial de Tarraco (Excavaciones Arqueológicas en España, 165). Madrid, 117-165.
AQUILUÉ, X., 1993b: La seu del Col-legi d'Arquitectes. Una intervenció arqueològica en el centre històric de Tàrraco. Tarragona.

AQUILUÉ, X., 1997: "Anàlisi comparativa de contextos ceràmics d'època tardo-romana (segles V-VI)", AADD: Contextos ceràmics d'època romana tardana i de l'alta edat mitjana (segles IV-X). Taula Rodona (Arqueomediterrània, 2). Barcelona, 83-100.

AQUILUÉ, X., 1998: "Sobre les darreres produccions de Terra Sigillata Africana”, Monografies d'Arqueologia Medieval i Postmedieval, 4. Barcelona, 11-19.

AQUILUÉ, X., 2003: "Estado actual de la investigación de la Terra Sigillata Africana en la Península Ibérica en los siglos VI-VII", Caballero, L; Mateos, P; Retuerce, M. (Eds.): Cerámicas tardorromanas y altomedievales en la Península Ibérica. Ruptura y continuidad (Anejos de Archivo Español de Arqueología, XXVIII). Madrid, 11-20.

AQUILUÉ, X., y BURÉS, L., 1999: "La ciutat en l'Antiguitat Tardana: fase V", Aquilué, X. (Dir): Intervencions arqueològiques a Sant Martí d'Empúries (1994-1996). De l'assentament precolonial a l'Empúries actual (Monografies Emporitanes, 9). Girona, 389-422.

ATLANTE, I, 1981. DDAA: Atlante delle forme ceramiche I. Ceramica fina romana nel bacino Mediterraneo (Medio e Tardo impero). Enciclopedia dell'arte antica classica e orientale. Roma.

BACARIA, A., 1993a: Importacions sudgàl-liques $i$ produccions locals de ceràmica estampada romana durant el Baix Imperi. Tesis doctoral (inédita), Universitat de Barcelona. Barcelona.

BACARIA, A., 1993b: "Tarraco i el comerç amb la Gàl-lia meridional durant el s. V d.C.: les importacions ceràmiques", Butlletí Arqueològic, època V, 15, 339-345.

BACARIA, A. et alii, 2005 (Bacaria, A., Torrent, C., Madrid, M., y Buxeda, J.): "Ceràmica de cuina del jaciment tardoromà de la Bastida (Rubí, Barcelona)", Gurt, J. M., Buxeda, J., y Cau, M. A. (Eds.): LRCW 1. Late Roman Coarse Wares, Cooking Wares and Amphorae in the Mediterranean: Archaeology and Archaeometry (Barcelona, 2001). Barcelona, 179-202.

BARRASETAS, E., 2001: "El jaciment de La Solana (Cubelles-El Garraf)", Guitart, J., Palet, J. M., y Prevosti, M.: Territoris antics a la Mediterrània i a la Cossetània oriental. Actes del Simposi Internacional d'Arqueologia del Baix Penedès (El Vendrell, novembre 2001). El Vendrell, 2001, 383-392.

BARRASETAS, E., y JÁRREGA, R., 1997: "La ceràmica trobada al jaciment de la Solana (Cubelles, Garraf)", AADD: Contextos ceràmics d'època romana tardana i de l'alta edat mitjana (segles IV-X). Taula Rodona (Arqueomediterrània, 2). Barcelona, 131-152. 
BARRASETAS, E., y JÁRREGA, R., 2004: "La Solana (Cubelles, Garraf)", Actes de les Jornades d'Arqueologia i Paleontologia 2001 (La Garriga). Comarques de Barcelona, 1996-2001. Barcelona. Vol. II, 722-729.

BONIFAY, M., y RIGOIR, Y., 1998: "Les Dérivées des sigillées paléochrétiennes", Bonifay, M., Carre, M. B., y Rigoir, Y. : Fouilles à Marseille. Les mobiliers (Ier-VIIe siècle ap. J.-C.. Collection Études Massaliètes, 5. Paris.

BOURGEOIS, A., 1970: "Céramique Paléochrétienne de Barcelone", Melanges de la Casa de Velázquez, T.VI, 53-77.

CABALLERO, L., 1972: "Cerámica sigillata gris y anaranjada paleocristiana en España”, Trabajos de Prehistoria, 29, 189-218.

CABALLERO, L., y ARGENTE, J. L., 1975: “Cerámica paleocristiana, gris y anaranjada, producida en España. Cerámicas tardo-romanas de la villa de Baños de Valdearados (Burgos)", Trabajos de Prehistoria, 32, 113-150.

CELA, X., y REVILLA, V., 2004: La transició del municipium d'Iluro a Alarona (Mataró). Cultura material i transformacions d'un espai urbà entre els segles V $i$ VII dC Mataró (Laietania, 15.

CLARIANA, J. F., y JÁRREGA, R., 1990: “Aportación al conocimiento de unas estructuras arquitectónicas tardorromanas del yacimiento arqueológico de Can Modolell (Cabrera de Mar, Barcelona)", Archivo Español de Arqueología, 63, 330-343.

CLARIANA, J. F., y JÁRREGA, R., 1994: "Estudi de la fase baix imperial de la vil.la romana de Torre Llauder (Mataró, El Maresme). Les ceràmiques", Laietània, 9, 253-289.

COLL, J. M., ROIG, J., y MOLINA, J. A., 1997: "Contextos ceràmics de l'antiguitat tardana del Vallès", AADD: Contextos ceràmics d'època romana tardana i de l'alta edat mitjana (segles IV-X). Taula Rodona (Arqueomediterrània, 2). Barcelona, 37-57.

COMAS, M., y PADRÓS, P., 1997: "Un context ceràmic del segle VI a Baetulo", AADD: Contextos ceràmics d'època romana tardana i de l'alta edat mitjana (segles IV-X). Taula Rodona (Arqueomediterrània, 2). Barcelona, 121-130.

COURTIEU, J. et alii, 1980 (Courtieu, J., Journet, C., Nicloux, J., Passelac, M., Rancoule, G., Rigoir, J. y Rigoir, Y.): "Dérivées des sigillées paléochrétiennes de l'Aude. Un atelier carcassonnais?", Bulletin de la Societé d'Études Scientifiques de l'Aude.

DELGADO, M., 1975: "Sigillée Late Roman C”, Delgado, M., Mayet, F., y Moutinho de Alarcão, A.: Fouilles de Conimbriga, IV. Les Sigillées. Paris, 285-291.

EMPEREUR, J. Y., y PICON, M., 1986: “A propos d'un nouvel atelier de Late Roman C", Fligina, 7, 143146.
ENRICH, J., y ENRICH, J., 1997: "Les ceràmiques comunes tardoromanes i altomedievals en el context de l'habitacle rural dispers de la Catalunya Central", AADD: Contextos ceràmics d'època romana tardana i de l'alta edat mitjana (segles $I V-X)$. Taula Rodona (Arqueomediterrània, 2). Barcelona, 21-36.

ENRICH, J., ENRICH, J., y PEDRAZA, L1., 1995: Vilaclara de Castellfollit del Boix. Un assentament rural de l'antiguitat tardana (Sèrie Interfàcies, 1). Igualada.

FÁBREGA, X., 1989: "Terra Sigillata Grisa i Ataronjada Estampades", TED'A: Un abocador del segle V d.C. en el Fòrum provincial de Tàrraco (Memòries d'excavació, 2). Tarragona, 156-172.

FERNÁNDEZ OCHOA, C., GARCÍA DÍAZ, P., y USCATESCU, A.: "Gijón en el período Tardoantiguo: cerámicas importadas de las excavaciones de Cimadevilla", Archivo Español de Arqueología, 65, 105-149.

GUITART, J., 1970: "Excavación en la zona sudeste de la villa romana de Sentromá (Tiana)", Pyrenae, 6, 111-116.

GUTIÉRREZ, S., 1998: "Il confronto con la Hispania Orientale: la ceramica nei secoli VI-VII", Saguì, L. (a cura di): Ceramica in Italia: VI-VII secolo. Atti del Convegno in onore di John W. Hayes (Roma, 1995). Firenze, 549-567.

HAYES, J. W., 1972: Late Roman Pottery. London.

HAYES, J. W., 1980: Supplement to Late Roman Pottery. London.

JÁRREGA, R., 1991: Cerámicas finas tardorromanas y del mediterráneo oriental en España. Estado de la cuestión (Anejos de Archivo Español de Arqueología, XI). Madrid.

JÁRREGA, R., 1992: Poblamiento y economía en la costa Este de la Tarraconense en época tardorromana (siglos $I V-V I$ ), Tesis doctoral (inédita), Universitat Autònoma de Barcelona. Bellaterra.

JÁRREGA, R., 2000: “Las cerámicas de importación en el Nordeste de la Tarraconense durante los siglos VI y VII d.C. Aproximación general", V Reunión de Arqueología Cristiana Hispánica (Cartagena, 16-19 d'abril de 1998). Barcelona, 467-483.

JÁRREGA, R., y CLARIANA, J. F., 1994: “Ceràmica Xipriota i Egípcia - B tardoromana a la comarca del Maresme", III Reunió d'Arqueologia Cristiana Hispànica (Maó, 12-17 setembre de 1988). Barcelona, 333-337.

JÁRREGA, R., y CLARIANA, J. F., 1996: “El jaciment arqueològic de Can Modolell (Cabrera de Mar, Maresme) durant l'Antiguitat Tardana. Estudi de les ceràmiques d'importació", Cypsela, XI, 125-152.

JUNYENT, E., y PÉREZ ALMOGUERA, A., 1994: “El bajo imperio ilerdense: las excavaciones de La Paeria”, III Reunió d'Arqueologia Cristiana Hispànica (Maó, 12-17 setembre de 1988). Barcelona, 127-150. 
LLINÀS, J., 1997: "La excavación de la carretera de San Martín de Ampurias (Gerona). Un ejemplo de la evolución de los contextos cerámicos durante la Antigüedad Tardía en el litoral catalán”, Archivo Español de Arqueología, 70, 149-169.

LÓPEZ MULLOR, A., y FIERRO, X., 1994: “Un conjunt ceràmic tancat del segle $\mathrm{V}$ trobat a la vil-la romana de Darró (Vilanova i la Geltrú)", Miscel-lània Penedesenca, 1994, 113-139.

LÓPEZ MULLOR, A., FIERRO, X., y CAIXAL, A., 1997: "Ceràmica dels segles IV al X procedent de les comarques de Barcelona", AADD: Contextos ceràmics d'època romana tardana $i$ de l'alta edat mitjana (segles IV-X). Taula Rodona (Arqueomediterrània, 2). Barcelona, 59-82.

LÓPEZ MULLOR, A. et alii, 2003 (López Mullor, A., Fierro, X., Enrich, J., Enrich, J., Sales, J., y Beltrán de Heredia, J.): "Cerámica tardorromana y altomedieval en la provincia de Barcelona. Siglos VII-X”, Caballero, L., Mateos, P., y Retuerce, M. (Eds.): Cerámicas tardorromanas y altomedievales en la Península Ibérica. Ruptura y continuidad (Anejos de Archivo Español de Arqueología, XXVIII). Madrid, 41-65.

LÓPEZ RODRÍGUEZ, J. M., 1985: Terra Sigillata Hispánica Tardía decorada a molde de la Península Ibérica. Salamanca.

MACIAS, J. M., 1999: La ceràmica comuna tardoantiga a Tàrraco. Anàlisi tipològica i històrica (segles V-VII) (TULCIS. Monografies Tarraconenses). Tarragona.

MACIAS, J. M., 2003: "Cerámicas tardorromanas de Tarragona: economía de mercado versus autarquía", Caballero, L., Mateos, P., y Retuerce, M. (Eds.): Cerámicas tardorromanas y altomedievales en la Península Ibérica. Ruptura y continuidad (Anejos de Archivo Español de Arqueología, XXVIII). Madrid, 21-39.

MACIAS, J. M., y REMOLÀ, J. A., 2005: "La cultura material de Tarraco-Tarracona (Hispania Tarraconenses-Regnum Visigothorum): cerámica común y ánforas", Gurt, J. M., Buxeda, J., y Cau, M. A. (Eds.): LRCW 1. Late Roman Coarse Wares, Cooking Wares and Amphorae in the Mediterranean: Archaeology and Archaeometry (Barcelona, 2001). Barcelona, 125-135.

MACIAS, J. M. et alii, 1997 (Macias, J. M., Menchon, J. J., Puche, J. M., y Remolà, J. A.): "Nous contextos ceràmics del segle IV i inicis del V en la província de Tarragona", AADD: Contextos ceràmics d'època romana tardana $i$ de l'alta edat mitjana (segles IV-X). Taula Rodona (Arqueomediterrània, 2). Barcelona, 153-177.

MANZANO, E., 2003: "Conclusiones. La cerámica de los siglos oscuros", Caballero, L., Mateos, P., y Retuerce, M. (Eds.): Cerámicas tardorromanas y altomedievales en la Península Ibérica. Ruptura y continuidad (Anejos de Archivo Español de Arqueología, XXVIII). Madrid, 541-557.

MARÍ, L., y REVILLA, V., 2003: "El Tossal del Moro (Corbins, Segrià). Economia i organització de l'espai en una vil.la del territori d'Ilerda", Actes de les Jornades d'Arqueologia i Paleontologia, 2000. Comarques de Lleida (Lleida, 30 de novembre-2 de desembre de 2000). Barcelona, 343-361.

MARTIN, A., 1998: "La Sigillata focese (Phocaean Red-Slip / Late Roman C Ware)", Saguì, L. (a cura di): Ceramica in Italia: VI-VII secolo. Atti del Convegno in onore di John W. Hayes (Roma, 1995). Firenze, 109-122.

MAYET, F., y PICON, M., 1986: "Une sigillée phocéenne tardive ( Late Roman $C$ ware ») et sa diffusion en occident", Fligina, 7, 129-143.

MÉNDEZ, R., 1983-1984: “Cerámica tipo Late Roman C en Cartagena", Pyrenae, 19-20, 147-156.

MÉNDEZ, R., 1988: "El tránsito a la dominación bizantina en Cartagena: las producciones cerámicas de la Plaza de los Tres Reyes", González Blanco, A. (Ed.): Arte y poblamiento en el SE peninsular durante los últimos siglos de civilización romana (Antigüedad y Cristianismo. Monografías sobre la Antigüedad Tardía, V). Murcia, 31-164.

MEZQUÍRIZ, M. A., 1961: Terra Sigillata Hispánica. Valencia.

MORRAL, E., NUIX, J., y MARTÍN, A., 1980: Excavació a la vil.la romana de Can Bosch de Basea (Terrassa). Terrassa.

MUÑOZ, A., 1989: "Altres produccions de vaixella de taula: Terra Sigillata Hispànica Tardana, Terra Sigillata Lucente, ceràmica vidriada Baix-imperial i imitacions de Terra Sigillata Africana”, TED'A: Un abocador del segle $V$ d.C. en el Fòrum provincial de Tàrraco (Memòries d'excavació, 2). Tarragona, 173-181.

MURCIA, A. J., y GUILLERMO, M., 2003: “Cerámicas tardorromanas y altomedievales procedentes del teatro romano de Cartagena", Caballero, L., Mateos, P., y Retuerce, M. (Eds.): Cerámicas tardorromanas y altomedievales en la Península Ibérica. Ruptura y continuidad (Anejos de Archivo Español de Arqueología, XXVIII). Madrid, 169-223.

MURCIA, A. J. et alii, 2005 (Murcia, A. J., Vizcaíno, J., García Lorca, S., y Ramallo, S.): "Conjuntos cerámicos tardíos de las excavaciones en el teatro romano de Cartagena", Gurt, J. M., Buxeda, J., y Cau, M. A. (Eds.): LRCW 1. Late Roman Coarse Wares, Cooking Wares and Amphorae in the Mediterranean: Archaeology and Archaeometry (Barcelona, 2001). Barcelona, 1-36.

NADAL, E., y SERRA, J., 2003: La vil-la tardoromana del Capell (Cervera, Segarra), Actes de les Jornades d'Arqueologia i Paleontologia, 2000. Comarques de 
Lleida (Lleida, 30 de novembre-2 de desembre de 2000). Barcelona, 389-409.

NAVEIRO, J., 1991: El comercio antiguo en el NW peninsular (Monografías Urgentes do Museu, 5). A Coruña.

NIETO, F. X., 1984: "Algunos datos sobre las importaciones de cerámica «Phocaean Red Slip » en la Península ibérica", Balgg, T. F. C., Jones, R. F. J., y Keay, S. J. (Eds.): Papers in Iberian Archaeology, Part II (B.A.R. International Series 193, II). Oxford, 540-551.

NIETO, F. X., 1993: El edificio “A” de la Ciudadela de Roses (la Terra Sigillata Africana) (C.I.A.G. Sèrie Monogràfica, 14). Girona.

NOLLA, J. M., 1984: "Excavaciones recientes en la ciudadela de Roses. El edificio Bajo-imperial", Balgg, T. F. C., Jones, R. F. J., y Keay, S. J. (Eds.): Papers in Iberian Archaeology, Part II, (B.A.R. International Series 193, II). Oxford, 430-459.

NOLLA, J. M., y CASAS, J., 1990: "El material ceràmic d'importació de la vil-la romana de Puig Rodon (Corçà, Baix Empordà). D'època severiana a la Baixa Antiguitat", Cypsela, VIII, 193-218.

NOLLA, J. M., y CASAS, J., 1997: "Material ceràmic del Puig de les Muralles (Puig Rom, Roses)", AADD: Contextos ceràmics d'època romana tardana i de l'alta edat mitjana (segles IV-X). Taula Rodona (Arqueomediterrània, 2). Barcelona, 7-19.

NOLLA, J. M., y PUERTAS, C., 1988: "Ceràmica africana i material d'importació Baix-imperial del jaciment del Camp de la Gruta (Torroella de Montgri, Baix Empordà)", Estudis sobre temes del Baix Empordà, 7, 29-77.

PADRÓ, J., y DE LA VEGA, J., 1989: “Treballs arqueològics a la cova Colomera o de les Gralles (Sant Esteve de la Sagra-Mur, Pallars Jussà)", Excavacions arqueològiques d'urgència a les comarques de Lleida (Excavacions Arqueològiques a Catalunya, 9). Barcelona, 9-68.

PASCUAL, J. et alii, 1997 (Pascual, J., Ribera, A., Rosselló, M., y Marot, T.): "València i el seu territori: contexts ceràmics de la fi de la romanitat a la fi del califat (270-1031)", AADD: Contextos ceràmics d'època romana tardana i de l'alta edat mitjana (segles IV-X). Taula Rodona (Arqueomediterrània, 2). Barcelona, 179-202.

PASCUAL, J., RIBERA, A., y ROSSELLÓ, M., 2003: "Cerámicas de la ciudad de Valencia entre la época visigoda y omeya (siglos VI-X)", Caballero, L., Mateos, P., y Retuerce, M. (Eds.): Cerámicas tardorromanas y altomedievales en la Península Ibérica. Ruptura y continuidad (Anejos de Archivo Español de Arqueología, XXVIII). Madrid, 67-117.

PAZ, J. A., 1991: Cerámica de mesa romana de los siglos III al VI d.C. en la provincia de Zaragoza. Zaragoza.
PÉREZ SUÑ̃́, J. M., 2003: "Materials ceràmics sense context estratigràfic: anàlisi tipològica", Revilla, V: Economia i poblament romà al curs inferior de l'Ebre. La vil.la de Casa Blanca (Tortosa). Tarragona, 169-243.

PREVOSTI, M., 1981a: Cronologia i poblament a l'àrea rural de Baetulo (Monografies Badalonines, 3 ). Badalona.

PREVOSTI, M., 1981b: Cronologia i poblament a l'àrea rural d'Iluro. Mataró.

PUIG, A. M., 1998: "El jaciment de Rhode a la fi de l'Antiguitat Tardana. Els contextos del segle VII dC a la Ciutadella de Roses (Alt Empordà, Girona)", Pyrenae, 29, 171-192.

RAMALLO, S., RUIZ VALDERAS, E., y BERROCAL, M. C., 1996: "Contextos cerámicos de los siglos VVII en Cartagena", Archivo Español de Arqueología, 69, 135-190.

RAMALLO, S., RUIZ VALDERAS, E., y BERROCAL, M. C., 1997: "Un contexto cerámico del primer cuarto del siglo VII en Cartagena", AADD: Contextos ceràmics d'època romana tardana $i$ de l'alta edat mitjana (segles IV-X). Taula Rodona (Arqueomediterrània, 2). Barcelona, 203-228.

RAYNAUD, C., 1993a: "D-S-P Dérivée de sigillée paléochrétienne", Py, M. (Ed.): Lattara 6. Dictionnaire des Céramiques Antiques en Méditerranée nordoccidentale (VII ème s. av. n. è.-VII ème s. de n. è.). Lattes, 410-418.

RAYNAUD, C., 1993b: "Céramique Late Roman C", Py, M. (Ed.): Lattara 6. Dictionnaire des Céramiques Antiques en Méditerranée nord-occidentale (VII ème s. av. n. è.-VII ème s. de n. è.). Lattes, 502-503.

REMOLÀ, J. A., 2000: Las ánforas tardo-antiguas en Tarraco (Hispania Tarraconensis). Siglos IV-VII d.C. Barcelona.

REVILLA, V., 2003: Economia i poblament romà al curs inferior de l'Ebre. La vil.la de Casa Blanca (Tortosa). Tarragona.

REVILLA, V. et alii, 1997 (Revilla, V., Martí, C., García Roselló, J., Pera, J., Cerdà, J. A., y Pujol, J.): "El nivell d'amortització del Cardo Maximus d'Iluro", AADD: Contextos ceràmics d'època romana tardana $i$ de l'alta edat mitjana (segles $I V-X$ ). Taula Rodona (Arqueomediterrània, 2). Barcelona, 101-119.

REYNOLDS, P., 1995: Trade in the Western Mediterranean, $A D$ 400-700: The ceramic evidence (B.A.R. International Series 604). Oxford, 1995.

RIGOIR, J., 1968: "Les sigillées paléochrétiennes grises et orangées", Galia, XXVI, 177-244.

RIGOIR, J., y RIGOIR, Y., 1971: "Les derivées des sigillées paléochrétiennes en Espagne", Rivista di Studi Liguri, XXXVII, 33-68. 
RIGOIR, J., RIGOIR, Y., y MEFRE, J. F., 1973: "Les dérivées des sigillées paléochrétiennes du groupe atlantique", Gallia, XXXI, 207-263.

RÜGER, Ch., 1968: "Romische keramik aus dem Kreuzgang der Kathedrale von Tarragona", Madrider Mitteilungen, 9, 237-258.

SERRANO, E., 2005: "Terra Sigillata Focense Tardía”, Roca, M., y Fernández García, M. I. (Coords.): Introducción al estudio de la cerámica romana. Una breve guía de referencia. Málaga, 305-316.

TED'A, 1989: Un abocador del segle $V$ d.C. en el Fòrum provincial de Tàrraco (Memòries d'excavació, 2). Tarragona.

USCATESCU, A., 2004: "La ciutat de Iesso durant l'Antiguitat Tardana: les novetats de la campanya d'excavacions de 1999', Guitart, J., y Pera, J. (Eds.): Iesso I. Miscel-lània arqueològica. BarcelonaGuissona, 11-142.

USCATESCU, A., y GARCÍA JIMÉNEZ, J., 2005: "Pottery wares from a fifth century deposit found at Iesso (Guissona, Lleida): archaeological and archaeometrical analyses", Gurt, J. M., Buxeda, J., y Cau, M. A. (Eds.): LRCW 1. Late Roman Coarse
Wares, Cooking Wares and Amphorae in the Mediterranean: Archaeology and Archaeometry (Barcelona, 2001). Barcelona, 81-103.

USCATESCU, A., FERNÁNDEZ OCHOA, C., y GARCÍA DÍAZ, P., 1994: "Producciones atlánticas de Terra Sigillata Gálica en la costa cantábrica de Hispania", Cuadernos de Prehistoria y Arqueología de la Universidad Autónoma de Madrid, 21, 183-234.

WAAGÉ, F. O., 1933: “The Roman and Byzantine Pottery. The American Excavations in the Athenian Agora: First Report", Hesperia, II, 279-328.

WAAGÉ, F. O., 1948: "Hellenistic and Roman Tableware of North Syria", Antioch-on-the-Orontes, IV (Part I, Ceramics and Islamic Coins). Princeton, 1-60.

YAÑEZ, C., 1997: "La ceràmica tardoromana del Roc d'Enclar", AADD: Roc d'Enclar. Transformacions d'un espai dominant (segles IV-XIX). Andorra, 250276.

Recibido el 26-06-07 Aceptado el 24-09-07 